\title{
Nonlinear viscoplasticity in ASPECT: benchmarking and applications to subduction
}

\author{
Anne Glerum ${ }^{1,2}$, Cedric Thieulot ${ }^{1}$, Menno Fraters ${ }^{1}$, Constantijn Blom ${ }^{1}$, and Wim Spakman ${ }^{1,3}$ \\ ${ }^{1}$ Earth Sciences, Utrecht University, Utrecht, the Netherlands \\ ${ }^{2}$ Geodynamic Modelling, GFZ German Research Centre for Geosciences, Potsdam, Germany \\ ${ }^{3}$ Centre of Earth Evolution and Dynamics (CEED), University of Oslo, 0316 Oslo, Norway
}

Correspondence: Anne Glerum (a.c.glerum@uu.nl)

Received: 26 January 2017 - Discussion started: 9 February 2017

Revised: 11 August 2017 - Accepted: 21 August 2017 - Published: 19 March 2018

\begin{abstract}
ASPECT (Advanced Solver for Problems in Earth's ConvecTion) is a massively parallel finite element code originally designed for modeling thermal convection in the mantle with a Newtonian rheology. The code is characterized by modern numerical methods, high-performance parallelism and extensibility. This last characteristic is illustrated in this work: we have extended the use of ASPECT from global thermal convection modeling to upper-mantlescale applications of subduction.

Subduction modeling generally requires the tracking of multiple materials with different properties and with nonlinear viscous and viscoplastic rheologies. To this end, we implemented a frictional plasticity criterion that is combined with a viscous diffusion and dislocation creep rheology. Because ASPECT uses compositional fields to represent different materials, all material parameters are made dependent on a user-specified number of fields.

The goal of this paper is primarily to describe and verify our implementations of complex, multi-material rheology by reproducing the results of four well-known twodimensional benchmarks: the indentor benchmark, the brick experiment, the sandbox experiment and the slab detachment benchmark. Furthermore, we aim to provide hands-on examples for prospective users by demonstrating the use of multimaterial viscoplasticity with three-dimensional, thermomechanical models of oceanic subduction, putting ASPECT on the map as a community code for high-resolution, nonlinear rheology subduction modeling.
\end{abstract}

\section{Introduction}

Earth is a complex dynamic system that deforms on a wide range of spatial and temporal scales. To obtain realistic predictions of this system from numerical simulations, it is key to capture the relevant aspects of this deformation behavior. Here we are concerned with the longer geological timescales of the subduction of lithospheric plates into the mantle. On such timescales, rock deformation is mostly nonelastic and characterized by unrecoverable solid-state creep and brittle-plastic failure (Ranalli, 1995; Karato, 2008; Burov, 2011). Strain-rate-dependent viscous deformation through the mechanism of solid-state creep is dominated by linear (Newtonian) diffusion creep and various forms of nonlinear high- and low-temperature dislocation creep (e.g., Ranalli, 1995; Burov, 2011). Plastic yielding occurs when large differential stresses cause rocks to fail beyond the creep regime by local brittle fracture or, at higher temperatures, through ductile homogeneous material flow (Ranalli, 1995; Karato, 2008).

The implementation of plastic yielding into numerical modeling software entails the definition of a yield criterion that the maximum stress must satisfy (Davis and Selvadurai, 2002). Several different plastic yield criteria, such as the Mohr-Coulomb, Drucker-Prager or the Griffith-Murrell criteria (see Braun, 1994; Braun and Beaumont, 1995; Davis and Selvadurai, 2002; Kachanov, 2004, and references therein), are commonly used. These formulations introduce a pressure dependence (frictional plasticity) in the yield criterion. Whereas failure behavior is similar between different rock types and depends primarily on pressure (Burov, 2011), deformation in the viscous creep regime (when stresses are 
below the plastic yield strength) requires the implementation of rheological descriptions varying with rock type, pressure, temperature, strain rate and other factors such as grain size and water content (Burov, 2011). The implementation of plastic failure and viscous creep complicates solving the governing equations of flow problems due to the nonlinear dependence of the so-called effective viscosity on the solution variables strain rate, pressure and temperature (Gerya, 2010). However, the necessity of using viscoplastic rheologies for simulating natural deformation processes, particularly of the lithosphere, is generally accepted.

Meanwhile, many 3-D geodynamical codes offer modeling using complex nonlinear viscoplastic rheology. Examples of such advanced codes are (in alphabetical order) CitcomCU (Moresi et al., 1996; Zhong, 2006), DOUAR (Braun et al., 2008), FANTOM (Thieulot, 2011), Fluidity (Davies et al., 2011), I3(E)LVIS (Gerya and Yuen, 2007), LaMEM (Kaus et al., 2016), MILAMIN (Dabrowski et al., 2008), pTaTin3D (May et al., 2015), Rhea (Burstedde et al., 2008), Slim3D (Popov and Sobolev, 2008), TERRA (Baumgardner, 1985; Davies et al., 2013) and Underworld2 (Moresi et al., 2007).

To this list we can now add the recent open-source code ASPECT (Advanced Solver for Problems in Earth's ConvecTion; Kronbichler et al., 2012), which was originally designed for modeling thermal convection in the mantle. ASPECT is a massively parallel finite element code that is based on state-of-the-art numerical methods, such as highperformance iterative and direct solvers and adaptive mesh refinement, to solve problems of both compressible and incompressible flow. It builds on tried and well-tested libraries such as dea l. I I (Bangerth et al., 2007; Arndt et al., 2017), Trilinos (Heroux et al., 2005; Heroux and Willenbring, 2012) and p4est (Burstedde et al., 2011) and is under constant development (Bangerth et al., 2017a; Dannberg and Heister, 2016; Rose et al., 2017; Heister et al., 2017).

However, ASPECT originally did not include modeling with multiple nonlinear viscoplastic materials as needed for long-term tectonics modeling, for example. Therefore, we implemented and benchmarked a frictional plasticity (Drucker-Prager) criterion that can be combined with a viscous creep rheology (diffusion, dislocation or composite creep) for any number of materials, allowing for fully thermomechanically coupled viscoplastic flow, on which we here report. There are two papers that use ASPECT that employ a simpler, one-material viscoplastic rheology for planetary convection (Tosi et al., 2015; Zhang and O'Neill, 2016). Here we focus on benchmarking our implementations in light of lithospheric deformation and these implementations as well as example model setups have or will become part of ASPECT, together with extensive documentation, providing hands-on applications of the code. We show that our viscoplastic rheology description enables the extension of applications beyond thermal mantle convection to detailed lithospheric subduction modeling.
We first present the algorithms underpinning the ASPECT code and our additions pertaining to rheology and compositional fields (Sect. 2). We then verify our implementations in Sect. 3 using four benchmarks of increasing complexity: the indentor benchmark (Thieulot et al., 2008; Thieulot, 2014), the brick experiment (Lemiale et al., 2008; Kaus, 2010), the numerical sandbox (Buiter et al., 2006) and the slab detachment benchmark (Schmalholz, 2011; Hillebrand et al., 2014). Finally, in Sect. 4 we present two 3-D subduction applications to showcase the new suite of possibilities made available through our additions and adaptations, and we discuss our overall results in Sect. 5.

\section{Methods}

A short summary of the governing equations solved by ASPECT is given in Sect. 2.1 (for more information the reader is referred to Kronbichler et al., 2012; Heister et al., 2017). Section 2.2 lists our specific additions to the code.

\subsection{ASPECT}

\subsubsection{Governing equations}

ASPECT can solve for both compressible and incompressible flow, but here we focus on the latter, adopting the Boussinesq approximation and assuming an infinite Prandtl number (i.e., inertial term is omitted). Heat production is not incorporated. This results in the following equations of conservation of momentum (Eq. 1), mass (Eq. 2) and energy (Eq. 3):

$$
\begin{aligned}
& -\nabla \cdot\left(2 \mu_{\mathrm{eff}} \dot{\epsilon}(\boldsymbol{u})\right)+\nabla P=\rho \boldsymbol{g}, \\
& \nabla \cdot \boldsymbol{u}=0, \\
& \frac{\partial T}{\partial t}+\boldsymbol{u} \cdot \nabla T-\nabla \cdot\left(\kappa+v_{h}(T)\right) \nabla T=0,
\end{aligned}
$$

where density $\rho=\rho_{0}\left(1-\alpha\left(T-T_{0}\right)\right)$. Other symbols are explained in Table 1. Artificial diffusivity $v_{h}$ is used to prevent oscillations due to the advection of the temperature field. It is calculated according to the entropy viscosity method of Guermond et al. (2011), as described in Kronbichler et al. (2012).

Similar to the description of temperature, distinct sets of material parameters are represented by compositional fields that are advected with the flow. For each field $c_{i}$, this formulation introduces an additional advection equation (Eq. 4) to the system of Eqs. (1)-(3) described above. As these equations contain no natural diffusion, artificial diffusivity $v_{h}$ is again introduced to stabilize advection:

$\frac{\partial c_{i}}{\partial t}+\boldsymbol{u} \cdot \nabla c_{i}-\nabla \cdot\left(v_{h}\left(c_{i}\right)\right) \nabla c_{i}=0$. 


\subsubsection{Solving the governing equations}

ASPECT solves the equations above using the finite element method: the domain is discretized into quadrilateral (in 2D) or hexahedral (in 3-D) finite elements and the solution (velocity, pressure, temperature and compositional fields) is expanded using Lagrange polynomials as interpolating basis functions. Default settings employ second-order polynomials for velocity, and first-order polynomials for pressure ( $Q_{2} Q_{1}$ elements, e.g., Donea and Huerta, 2003), and secondorder polynomials for temperature and composition. Unless stated otherwise, these default polynomial degrees are used in the following. The linearized Stokes system is solved in a procedure involving the iterative Flexible GMRES (FGMRES) solver with an inexact right preconditioner. For details on the construction of the preconditioner, see Kronbichler et al. (2012). A cheap Stokes solve option in which the preconditioner employs only one $\mathrm{V}$ cycle is available. The number of such FGMRES iterations before switching to the more expensive preconditioner is set to 0 in this paper, unless stated otherwise. The GMRES method with an incomplete LU decomposition preconditioner is used for the temperature and composition systems. Nonlinearities in the rheology are resolved with Picard-type (fixed-point) iterations, iteratively updating the velocity and pressure, strain rate and viscosity (Ismail-Zadeh and Tackley, 2010) until the relative nonlinear residual for iteration $\mathrm{i} \frac{\left\|\mathbf{A}\left(\boldsymbol{x}_{i-1}\right) \boldsymbol{x}_{i-1}-\boldsymbol{b}\right\|_{2}}{\left\|\mathbf{A}\left(\boldsymbol{x}_{0}\right) \boldsymbol{x}_{0}-\boldsymbol{b}\right\|_{2}}$ has fallen below a user-set tolerance (default value of $10^{-6}$ ), or the user-specified maximum number of iterations (NIs) is reached. The initial residual $\left\|\mathbf{A}\left(\boldsymbol{x}_{0}\right) \boldsymbol{x}_{0}-\boldsymbol{b}\right\|_{2}$ is computed with zero velocities and a lithostatic pressure profile calculated at the center horizontal coordinate. $\boldsymbol{x}$ contains the velocity and pressure solutions of the previous iteration, $\boldsymbol{b}$ represents the right-hand side of the Stokes equations and $\mathbf{A}$ is the Stokes part of the system matrix.

\subsection{Additions to ASPECT}

\subsubsection{Nonlinear rheologies}

The ASPECT code is divided into different modules for boundary conditions, initial conditions, mesh refinement etc. Each module comprises of several plug-ins providing different implementations (e.g., constant vs. space- and timedependent boundary conditions), to which the user can add its own if more functionality is needed. Rheologies are implemented within the so-called Material model module. Plug-ins in this module must provide functions that compute the viscosity, density, thermal conductivity, thermal diffusivity, specific heat and the thermal expansion coefficient at the quadrature points. The solution variables $T, P$ and $c_{i}$ as well as the derived strain rate $\dot{\epsilon}(\boldsymbol{u})$ and the position are available to compute these material properties. This then provides a straightforward way of implementing nonlinear rheologies, which we have taken advantage of.
Table 1. Definition of symbols.

\begin{tabular}{|c|c|c|}
\hline Parameter name & Symbol & Unit \\
\hline Activation volume* & $V_{\mathrm{df} \mid \mathrm{dl}}$ & $\mathrm{m}^{3} \mathrm{~mol}^{-1}$ \\
\hline Activation energy* & $Q_{\mathrm{df} \mid \mathrm{dl}}$ & $\mathrm{J} \mathrm{mol}^{-1}$ \\
\hline Artificial diffusivity & $v_{h}$ & $\mathrm{~m}^{2} \mathrm{~s}^{-1}$ \\
\hline Burgers vector length & $b$ & $0.5 \times 10^{-9} \mathrm{~m}$ \\
\hline Cohesion* & $C$ & $\mathrm{~Pa}$ \\
\hline Compositional field $i$ & $c_{i}$ & - \\
\hline Effective deviatoric strain rate & $\dot{\epsilon}_{\mathrm{e}}=\sqrt{\frac{1}{2} \dot{\epsilon}_{i j}^{\prime} \dot{\epsilon}_{i j}^{\prime}}$ & $\mathrm{s}^{-1}$ \\
\hline Effective viscosity & $\mu_{\mathrm{eff}}^{\mathrm{vsc}|\mathrm{df}| \mathrm{dl}|\mathrm{cp}| \mathrm{pl} \mid \mathrm{vp}}$ & Pas \\
\hline Gas constant & $R$ & $8.314 \mathrm{~J} \mathrm{~K}^{-1} \mathrm{~mol}^{-1}$ \\
\hline Grain size & $d$ & $0.01 \mathrm{~m}$ \\
\hline Grain size exponent & $m$ & - \\
\hline Gravity vector & $g$ & $\mathrm{~ms}^{-2}$ \\
\hline Initial effective strain rate & $\dot{\epsilon}_{\text {init }}$ & $\mathrm{s}^{-1}$ \\
\hline Initial linear viscosity* & $\mu_{\text {init }}$ & Pas \\
\hline Internal angle of friction* & $\phi$ & 1as \\
\hline NI convergence criterion & $\epsilon_{\mathrm{u}}$ & - \\
\hline Minimum and maximum viscosity & $\mu_{\min \mid \max }$ & Pas \\
\hline Pre-exponential factor & $A_{\mathrm{df} \mid \mathrm{dl}}$ & $\mathrm{Pa}^{-\mathrm{n}} \mathrm{s}^{-1}$ \\
\hline Prefactor* & $B_{\mathrm{df} \mid \mathrm{dl}}$ & $\mathrm{Pa}^{-\mathrm{n}} \mathrm{s}^{-1}$ \\
\hline Reference density* & $\rho_{0}$ & $\mathrm{~kg} \mathrm{~m}^{-3}$ \\
\hline Reference temperature* & $T_{0}$ & $\mathrm{~K}$ \\
\hline Reference viscosity & $\mu_{\text {ref }}$ & Pas \\
\hline Scaling factor* & $\beta_{\mathrm{df} \mid \mathrm{dl}}$ & - \\
\hline Shear modulus & $K$ & $80 \mathrm{GPa}$ \\
\hline Specific heat* & $c_{\mathrm{p}}$ & $\mathrm{Jkg}^{-1} \mathrm{~K}^{-1}$ \\
\hline Strain rate tensor & $\dot{\epsilon}$ & $\mathrm{s}^{-1}$ \\
\hline Stress exponent* & $n$ & - \\
\hline Temperature & $T$ & $\mathrm{~K}$ \\
\hline Thermal conductivity* & $k$ & $\mathrm{~W} \mathrm{~m}^{-1} \mathrm{~K}^{-1}$ \\
\hline Thermal diffusivity & $\kappa=\frac{k}{\rho c_{p}}$ & $\mathrm{~m}^{2} \mathrm{~s}^{-1}$ \\
\hline Thermal expansivity* & $\alpha{ }^{p t p}$ & $\mathrm{~K}^{-1}$ \\
\hline Time & $t$ & $\mathrm{~s}$ \\
\hline Total pressure & $P$ & $\mathrm{~Pa}$ \\
\hline Velocity vector & $u$ & $\mathrm{~ms}^{-1}$ \\
\hline Viscosity & $\mu$ & Pas \\
\hline Yield strength & $\sigma_{y}$ & $\mathrm{~Pa}$ \\
\hline
\end{tabular}

Deformation of materials on longer timescales is predominantly defined by brittle fracture or viscous creep in terms of diffusion and dislocation creep at relatively low stresses (Karato, 2008). We thus implement three basis rheologies that can be combined into more complex ones:

1. grain boundary or bulk diffusion creep

2. power-law dislocation creep

3. plastic yielding.

Rheologies 1 and 2 can be conveniently formulated with one equation (Karato and Wu, 1993; Karato, 2008):

$\mu_{\mathrm{eff}}^{\mathrm{vsc}}=\frac{1}{2} K\left(\frac{d}{b}\right)^{m / n}\left(\frac{1}{A}\right)^{1 / n} \dot{\epsilon}_{\mathrm{e}}^{(1-n) / n} \exp \left(\frac{Q+P V}{n R T}\right)$,

where in case of diffusion creep, $n=1$ and $m>0$, while for dislocation creep $n>1$ and $m=0$. See Table 1 for the definition of the symbols used. The effective deviatoric strain rate 
is defined as $\dot{\epsilon}_{\mathrm{e}}=\sqrt{\frac{1}{2} \dot{\epsilon}_{i j}^{\prime} \dot{\epsilon}_{i j}^{\prime}}$. We simplify Eq. (5) by defining prefactor $B$ as $\left(\frac{1}{B}\right)^{\frac{1}{n}}=\left(\frac{d^{m} K^{n}}{A b^{m}}\right)^{\frac{1}{n}}$ and add a scaling factor $\beta$ to easily tune the effective viscosity:

$\mu_{\mathrm{eff}}^{\mathrm{df} \mid \mathrm{dl}}=\frac{1}{2} \beta^{\mathrm{df} \mid \mathrm{dl}}\left(\frac{1}{B^{\mathrm{df} \mid \mathrm{dl}}}\right)^{1 / n} \dot{\epsilon}_{\mathrm{e}}^{(1-n) / n} \exp \left(\frac{Q^{\mathrm{df} \mid \mathrm{dl}}+P V^{\mathrm{df} \mid \mathrm{dl}}}{n R T}\right)$.

The superscript "df" here indicates diffusion creep and "dl" indicates dislocation creep.

Plastic yielding (rheology 3 ) is implemented by locally rescaling the effective viscosity in such a way that the stress does not exceed the yield stress, also known as the viscosity rescaling method (Willett, 1992; Kachanov, 2004). The effective plastic viscosity is thus given by

$\mu_{\mathrm{eff}}^{\mathrm{pl}}=\frac{\sigma_{y}}{2 \dot{\epsilon}_{\mathrm{e}}}$,

where $\sigma_{y}$ is the yield value. In our implementation it is defined by the Drucker-Prager criterion (Davis and Selvadurai, 2002):

$\sigma_{y}=C \cos (\phi)+\sin (\phi) P$,

$\sigma_{y}=\frac{6 C \cos (\phi)}{\sqrt{3}(3-\sin (\phi))}+\frac{6 \sin (\phi) P}{\sqrt{3}(3-\sin (\phi))}$,

where dilatancy is neglected for simplicity. In case the internal friction angle $\phi$ is zero, this criterion reverts back to the von Mises criterion in 2-D. In 2-D it is set to equal the Mohr-Coulomb criterion, while in 3-D it circumscribes the Mohr-Coulomb yield surface (de Souza Neto et al., 2008).

Both types of viscous creep act simultaneously (Karato, 2008) under the same deviatoric stress, so the contributions of diffusion $\mu_{\mathrm{eff}}^{\mathrm{df}}$ and dislocation $\mu_{\mathrm{eff}}^{\mathrm{dl}}$ creep to the effective viscosity are harmonically averaged into a composite viscosity (van den Berg et al., 1993):

$\mu_{\mathrm{eff}}^{\mathrm{cp}}=\left(\frac{1}{\mu_{\mathrm{eff}}^{\mathrm{df}}}+\frac{1}{\mu_{\mathrm{eff}}^{\mathrm{dl}}}\right)^{-1}$.

To combine plastic yielding and viscous creep, we assume they are independent (parallel) processes (Karato, 2008), i.e., the mechanism resulting in the lowest effective viscoplastic viscosity is favored:

$\mu_{\mathrm{eff}}^{\mathrm{vp}}=\min \left(\mu_{\mathrm{eff}}^{\mathrm{cp}}, \mu_{\mathrm{eff}}^{\mathrm{pl}}\right)$.

However, for a smoother transition between the different deformation regimes (which should be easier for the numerical scheme to solve), we also experimented with a harmonic average (following Ismail-Zadeh and Tackley, 2010):

$\mu_{\mathrm{eff}}^{\mathrm{vp}}=\left(\frac{1}{\mu_{\mathrm{eff}}^{\mathrm{cp}}}+\frac{1}{\mu_{\mathrm{eff}}^{\mathrm{pl}}}\right)^{-1}=\left(\frac{1}{\mu_{\mathrm{eff}}^{\mathrm{df}}}+\frac{1}{\mu_{\mathrm{eff}}^{\mathrm{dl}}}+\frac{1}{\mu_{\mathrm{eff}}^{\mathrm{pl}}}\right)^{-1}$.
Because of the strain rate dependence of viscosity and the lack of an initial guess for the strain rate for the first time step, a user-defined initial viscosity $\mu_{\text {init }}$ is adopted for each compositional field, or an initial uniform strain rate $\dot{\epsilon}_{\text {init }}$ is set. We find that the values of $\mu_{\text {init }}$ and $\dot{\epsilon}_{\text {init }}$ can significantly affect the compute time of the first time step. During subsequent time steps, the strain rate of the previous time step is used as an initial guess for the iterative process.

The final effective viscosity $\mu_{\mathrm{eff}}^{\mathrm{vp}}$ is capped by the userdefined minimum viscosity $\mu_{\min }$ and maximum viscosity $\mu_{\max }$ to avoid extremely low or high viscosity values due to possible velocity anomalies feeding back into the rheology as well as large viscosity jumps and thus ensure stability of the numerical scheme:

$$
\begin{aligned}
& \mu_{\text {eff }}=\min \left(\max \left(\mu_{\mathrm{eff}}^{\mathrm{vp}}, \mu_{\min }\right), \mu_{\max }\right) \quad \text { or } \\
& \mu_{\mathrm{eff}}=\mu_{\min }+\left(\frac{1}{\mu_{\mathrm{max}}}+\frac{1}{\mu_{\mathrm{eff}}^{\mathrm{vp}}}\right)^{-1} .
\end{aligned}
$$

We have successfully run the models presented here with overall viscosity contrasts of up to 7 orders of magnitude. Such a range covers the mantle viscosity profiles suggested in most literature, for example as summarized in Cizkova et al. (2012), and we assume that viscosities higher than $\mu_{\max }$ do not change the behavior significantly.

\subsubsection{Multiple compositional fields}

Lithospheric geodynamic models often require the specification of materials with different properties, for example a light and weak upper crust versus a denser and stronger lithospheric mantle. To provide the functionality needed for geodynamic modeling, all major material properties of our Material model plug-in depend on any number of fields, as defined by the user (composition-dependent parameters are denoted with an asterisk in Table 1).

The use of multiple compositional fields raises the question of how to average their properties (in our case viscosity, specific heat, thermal conductivity, thermal expansivity and density). We have implemented the four averaging schemes commonly referred to in the literature (e.g., Deubelbeiss and Kaus, 2008; Schmeling et al., 2008) for computing the viscosity used in Eq. (13) or (14): 
$\mu_{\mathrm{eff}}^{\mathrm{vp}}=\frac{\sum_{i=1}^{\mathrm{nc}} c_{i}}{\sum_{i=1}^{\mathrm{nc}} \frac{c_{i}}{\mu_{\mathrm{eff}_{i}}}}$,

(harmonic)

$\mu_{\mathrm{eff}}^{\mathrm{vp}}=10\left(\frac{\sum_{i=1}^{\mathrm{nc}} c_{i} \log _{10}\left(\mu_{\mathrm{eff}}^{\mathrm{vp}}\right)}{\sum_{i=1}^{\mathrm{nc}} c_{i}}\right)$,

(geometric)

$\mu_{\mathrm{eff}}^{\mathrm{vp}}=\frac{\sum_{i=1}^{\mathrm{nc}} c_{i} \mu_{\mathrm{eff}}^{\mathrm{vp}}}{\sum_{i=1}^{\mathrm{nc}} c_{i}}$,

(arithmetic)

$\mu_{\mathrm{eff}}^{\mathrm{vp}}=\mu_{k}$ with $k: c_{k} \geq c_{i}, i=1, \cdots, n c, \quad$ (infinity norm)

where "nc" is the total number of compositional fields $c_{i}$ in the domain. Note that each field $c_{i}$ is initialized with values on the interval $[0,1]$ and capped values $0 \leq c_{i} \leq 1$ are used for averaging, as compositional field values may come to slightly exceed this interval over time despite artificial diffusion (Eq. 4). The $\mu_{\mathrm{eff}_{i}}^{\mathrm{vp}}$ value is obtained by evaluating Eqs. (11) or (12) using the material constants of composition $i$. The other material properties are arithmetically averaged or, in case the viscosity averaging method is set to Eq. (18), averaged using this infinity norm.

The methods above have been shown to affect model results in the context of subduction: Schmeling et al. (2008) showed that the subduction process can be up to 3 times faster between one averaging method and the other, and the effect of mesh resolution on subduction evolution varies per method as well. Unless stated otherwise, we use the infinity norm rule in this paper; for a discussion of this choice, see Appendix A.

\section{Nonlinear rheology benchmarks}

To test and verify our implementation of multi-material viscoplastic rheologies, we performed four 2-D experiments: the indentor benchmark, the brick experiment, the numerical sandbox and the slab detachment experiment. The experiments increase in the number of materials and in the complexity of the rheology used, as outlined in Table 2. Consequently, each experiment highlights different parts of the implementation and the functionalities of ASPECT.

All experiments were conducted on an in-house computer consisting of 1 Dell PE-R515 master node and 15 Dell PEC6145 compute servers made up of $2 \times 4$ AMD Opteron 6136 CPUs with QLogic InfiniBand QDR interconnect. ASPECT was compiled using GCC 4.9.2.

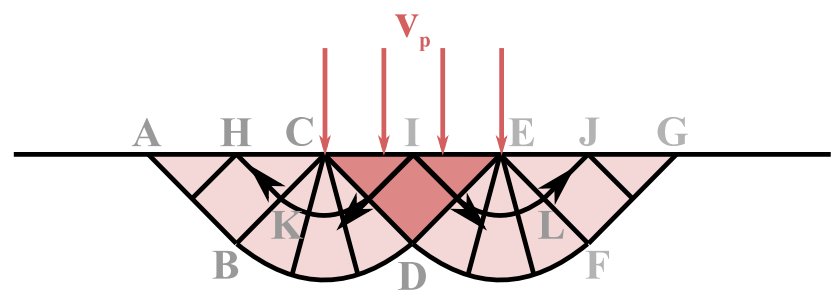

Figure 1. Prandtl's analytical solution of a rigid die indenting a rigid-plastic half space (Davis and Selvadurai, 2002; Kachanov, 2004; Thieulot et al., 2008). Dark red arrows indicate the prescribed punch velocity $v_{\mathrm{p}}$. The shaded area inside CDE has a resulting velocity of $v_{\mathrm{CDE}}=v_{\mathrm{p}}$, while velocities in the lightest shaded areas are $v_{\mathrm{ABDC}}=v_{\mathrm{EDFG}}=\frac{v_{\mathrm{p}}}{\sqrt{2}}$. Pressure at point $\mathrm{I}$ is $P_{\mathrm{I}}=\sigma_{y}(1+\pi)$ and $P_{\mathrm{ABC}}=P_{\mathrm{EFG}}=\sigma_{y}$.

\subsection{The indentor benchmark}

In the indentor benchmark, a rigid indentor "punches" a rigid-plastic half space. The exact solution to this boundary value problem is given by slip-line field theory (Davis and Selvadurai, 2002; Kachanov, 2004; Thieulot et al., 2008, Appendix B). The analytical solution (Fig. 1) is characterized by three observations:

1. The angles of the shear bands stemming from the edges of the indented area are $45^{\circ}$.

2. The pressure at the surface in the center of the punch (I) and the pressure in triangles $\mathrm{ABC}$ and EFG are $P_{\mathrm{I}}=$ $\sigma_{y}(1+\pi)$ and $P_{\mathrm{ABC}}=P_{\mathrm{EFG}}=\sigma_{y}$, respectively.

3. The velocity magnitude in areas $\mathrm{CDE}$ and $\mathrm{ABDC} \&$ $\mathrm{EDFG}$ is $v_{\mathrm{CDE}}=v_{\mathrm{p}}$ and $v_{\mathrm{ABDC}}=v_{\mathrm{EDFG}}=\frac{v_{\mathrm{p}}}{\sqrt{2}}$, respectively.

\subsubsection{Model setup}

The numerical setup of the instantaneous indentor benchmark comprises a 2-D unit square of purely plastic von Mises material, i.e., its yield value $\sigma_{y}$ is independent of pressure and remains constant. The material's upper boundary is punched along a distance $p$ by prescribing an inward vertical velocity $v_{\mathrm{p}}$ on the otherwise open (stress-free) boundary (see Fig. 2a). The horizontal component of velocity along $p$ is either set to zero or left free to implement the so-called "rough" and "smooth" punch (Lliboutry, 1987; Lee et al., 2005; Thieulot et al., 2008), respectively, where the smooth punch assumes a frictionless contact between the punched medium and the indentor. Model and numerical parameters of the performed indentor experiments are presented in Table 3.

\subsubsection{Model results compared to the analytical solution}

Figure 3 shows the model results for a rough (left column) and smooth (right column) punch. The solutions obtained 
Table 2. Characteristics of performed experiments.

\begin{tabular}{lclcll}
\hline Benchmark & nc* & Rheology & $\begin{array}{c}\text { Time } \\
\text { stepping }\end{array}$ & Solution & References \\
\hline Indentor & 1 & Rigid plastic & no & Analytical & Kachanov (2004); Thieulot et al. (2008) \\
Brick & 2 & Linear viscous, frictional plastic & no & Theory + other codes & Lemiale et al. (2008); Kaus (2010) \\
Sandbox & 3 & $\begin{array}{l}\text { Linear viscous, frictional plastic } \\
\text { including sticky air }\end{array}$ & yes & Other codes & Buiter et al. (2006); Thieulot (2011) \\
Detachment & 2 & Power-law viscous & yes & Analytical + other codes & Schmalholz (2011); Hillebrand et al. (2014) \\
\hline
\end{tabular}

*nc: number of compositions. None of the benchmarks include temperature effects in the rheology.

Table 3. The indentor benchmark model parameters.

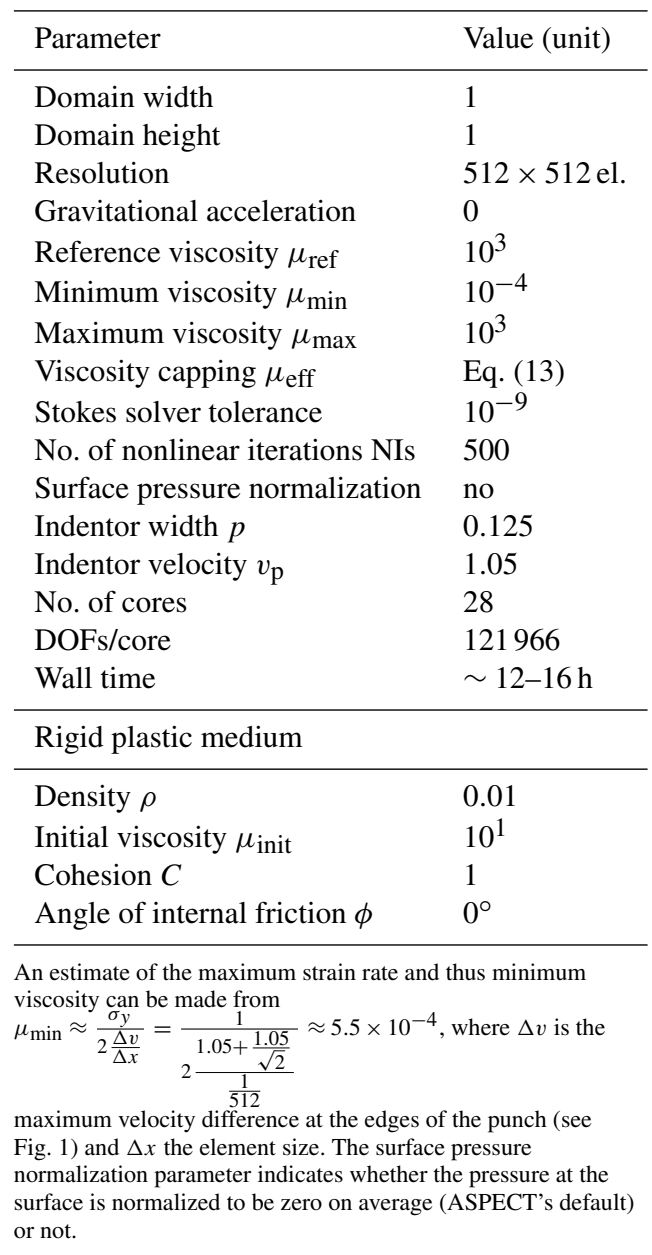

agree with the analytical solution according to criteria 1-3 listed above. Outside the slip lines, viscosity is uniformly high. The low-viscosity shear bands fit the analytical slip lines well (Fig. 3a and $\mathrm{f}$ ) and stem from the edges of the indentor at a $45^{\circ}$ angle with respect to the top of the medium (Fig. 3b and g). For a rough punch, measurements of pressure in point $\mathrm{I}$ and velocity in points $\mathrm{K}$ and $\mathrm{L}$ deviate from the analytical solution by about 15 and $1 \%$, respectively, but the block-like behavior of triangle CDE is evident (Fig. 3c). The analytical solution is reproduced with errors $<0.14 \%$ for a

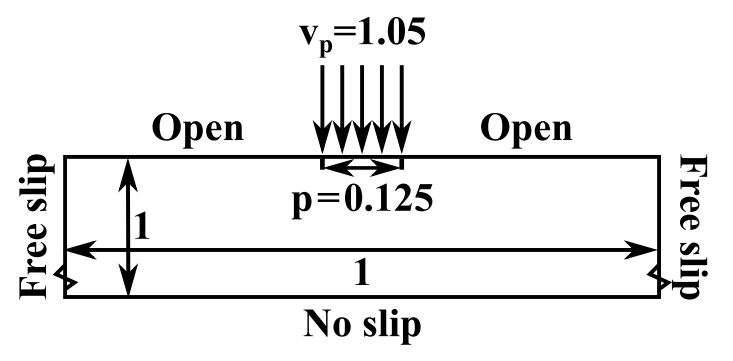

Figure 2. The indentor benchmark model setup: a unit square with free-slip vertical and no-slip lower boundaries. The punch area has a prescribed vertical velocity $v_{\mathrm{p}}$; the rest of the upper boundary is open.

smooth punch, but the velocity vectors in Fig. 3h show some horizontal motion of triangle CDE and the velocity field is more diffuse.

When using 200 cheap Stokes iterations for the smooth punch, results are not changed, but wall time is about 1.6 times longer. Using harmonic averaging of the material properties as discussed in Heister et al. (2017) increases the velocity error for the smooth punch to $\sim 1 \%$, but reduces wall time about 4.7 times. Loosening the linear Stokes solver tolerance by 1 order of magnitude to $10^{-8}$ reduces the wall time of the rough punch by a factor of 1.6 , while keeping the velocity error $<1 \%$.

\subsubsection{Discussion}

ASPECT successfully reproduces the analytical solution of Prandtl for the rigid-plastic indentor benchmark, a problem with mixed boundary conditions and a nonlinear rigid-plastic rheology with overall viscosity contrasts of 6 orders of magnitude.

It should be noted that there exists a second end-member solution geometry for the smooth punch problem: Hill's solution (Kachanov, 2004). Although Kachanov (2004) argues that Hill's solution is probably more correct when considering elasticity theory, and Lliboutry (1987) lists Hill's solution for the smooth punch, other numerical studies do not recover this slip-line geometry in 2-D either. In fact, our Prandtl shear band geometry compares well with results of Gerbault et al. (1998, Fig. 6b, smooth), Huh et al. (1999, Fig. 1, 

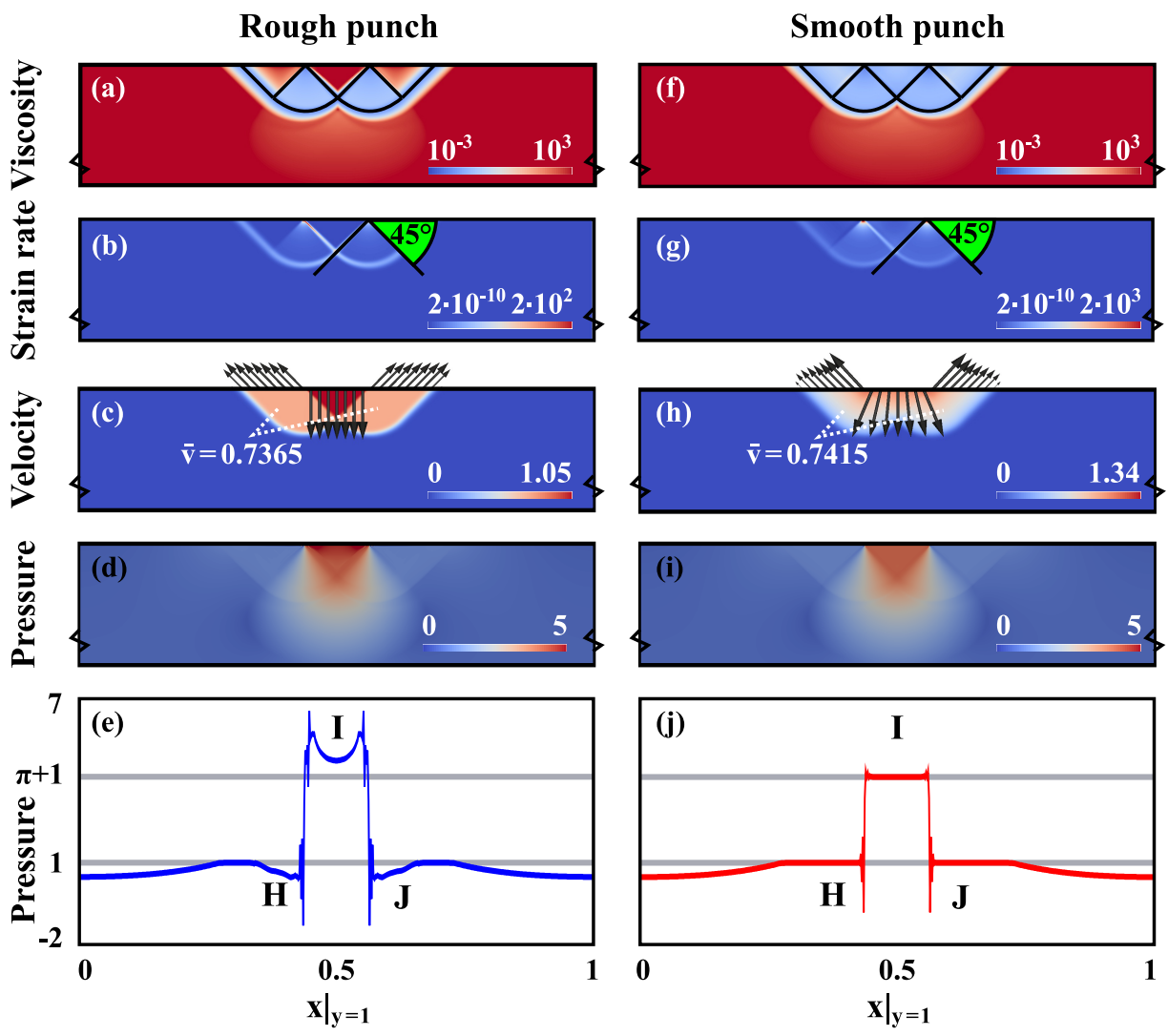

Figure 3. The punch benchmark results after 500 NIs for a rough punch (left column) and a smooth punch (right column). (a, f) Viscosity field with analytical slip lines. (b, g) Strain rate norm $(\sqrt{\dot{\epsilon}: \dot{\epsilon}})$ with measured shear band angles. (c, h) Velocity magnitude with velocity vectors along the surface of the domain and velocity measurements in points K and L. (d, i) Pressure field. (e, j) Pressure along the surface of the domain (colored line) and analytical solution values $\pi+1$ and 1 (grey lines). Rough punch: $P_{\mathrm{I}}=4.7382$ and $P_{\mathrm{H}}=P_{\mathrm{J}}=0.6224$. Smooth punch: $P_{\mathrm{I}}=4.1415$ and $P_{\mathrm{H}}=P_{\mathrm{J}}=0.9999$.

smooth), Christiansen and Pedersen (2001, Fig. 10, smooth), Zienkiewicz et al. (1995, Figs. 24-27, rough), Gourvenec et al. (2006, Fig. 6a, rough), and Yu and Tin-Loi (2006, Fig. 11, rough).

The indentor experiment performed also shows a tradeoff between accuracy in pressure and velocity measurements and the rigid-plastic-like behavior of the medium (compare left and right column of Fig. 3). This same dichotomy is seen however in other studies that performed the experiment. Note, for example, the continuous velocity vectors in Huh et al. (1999). Also, Thieulot (2014) shows that the pressure under the punch improves from a $15 \%$ error to a mere $0.5 \%$ error when switching from a rough to a smooth footing.

\subsection{The brick experiment}

As brittle failure in rocks is more appropriately described by pressure-dependent plasticity than by the perfectly plastic deformation (Gerbault et al., 1998) used in the punch problem, our material model plug-in includes frictional plasticity. The brick benchmark has been used to investigate the numerical stability of shear band angles $\theta$ and their dependence on the internal angle of friction $\phi$ by Kaus (2010) and references therein. Three theoretical relationships have been proposed (Vermeer, 1990):

$$
\begin{aligned}
& \text { 1. } \theta=45 \pm \frac{\psi}{2} \text { (Roscoe) } \\
& \text { 2. } \theta=45 \pm \frac{\phi+\psi}{4} \text { (Arthur) } \\
& \text { 3. } \theta=45 \pm \frac{\phi}{2} \text { (Coulomb), }
\end{aligned}
$$

where $\psi$ is the dilation angle (assumed to be zero in our case of incompressibility).

\subsubsection{Model setup}

In our instantaneous version of the brick benchmark, a viscous-frictional plastic medium with a small viscous inclusion at the bottom boundary (Fig. 4) is either compressed or extended (Lemiale et al., 2008; Kaus, 2010). Strain softening of the cohesion and angle of internal friction of the medium is not incorporated. Compression and extension are prescribed through constant kinematic boundary conditions on the vertical domain walls. The bottom boundary of the 
Table 4. The brick benchmark model parameters.

\begin{tabular}{|c|c|}
\hline Parameter & Value (unit) \\
\hline Domain width $L_{x}$ & $40 \mathrm{~km}$ \\
\hline Domain height & $10 \mathrm{~km}$ \\
\hline Resolution & $128 \times 32-1024 \times 256 \mathrm{el}$. \\
\hline Gravitational acceleration & $10 \mathrm{~ms}^{-2}$ \\
\hline Applied horizontal velocity $v_{x}$ & $2 \times 10^{-11} \mathrm{~ms}^{-1}$ \\
\hline Reference viscosity $\mu_{\text {ref }}$ & $10^{24} \mathrm{Pas}$ \\
\hline Effective viscosity $\mu_{\text {eff }}^{\mathrm{vp}}$ & Eq. (12) \\
\hline Minimum viscosity $\mu_{\min }$ & $10^{19} \mathrm{Pas}$ \\
\hline Maximum viscosity $\mu_{\max }$ & $10^{26} \mathrm{Pas}$ \\
\hline Viscosity capping $\mu_{\mathrm{eff}}$ & Eq. (13) \\
\hline Stokes solver tolerance & $10^{-7}$ \\
\hline No. of nonlinear iterations (NIs) & $10^{3}$ \\
\hline No. of cores & 28 \\
\hline Wall time & $5 \mathrm{~min}-66 \mathrm{~h}$ \\
\hline DOFs/core & $2691-42466$ \\
\hline \multicolumn{2}{|l|}{ Viscoplastic medium } \\
\hline Constant density $\rho$ & $2700 \mathrm{~kg} \mathrm{~m}^{-3}$ \\
\hline Initial viscosity $\mu_{\text {init }}$ & $10^{23} \mathrm{Pas}$ \\
\hline Linear viscous viscosity $\mu$ & $10^{25} \mathrm{Pas}$ \\
\hline Cohesion $C$ & $40 \mathrm{MPa}$ \\
\hline Angle of internal friction $\phi$ & $0-30^{\circ}$ \\
\hline \multicolumn{2}{|l|}{ Viscous inclusion } \\
\hline Constant density $\rho$ & $2700 \mathrm{~kg} \mathrm{~m}^{-3}$ \\
\hline Linear viscous viscosity $\mu$ & $10^{20} \mathrm{Pas}$ \\
\hline
\end{tabular}

The background strain rate resulting from the boundary conditions of $\frac{2 v_{x}}{L_{x}}=\frac{4 \times 10^{-11}}{40000}=10^{-15} \mathrm{~s}^{-1}$ can be used as the initial strain rate. The maximum strain rate over all mesh resolutions can be estimated from $\frac{\Delta v}{\Delta x}=\frac{4 \times 10^{-11}}{40000}=1.024 \times 10^{-12} \mathrm{~s}^{-1}$. Yield stress $\sigma_{y}$ during the first iteration $\frac{\Delta v}{\Delta x}=\frac{40000}{1024}$

will be minimal at the top of the domain (zero pressure) for the highest friction angle, so that the minimum viscosity over all runs will be $1.7 \times 10^{19} \mathrm{Pas}$. The linear viscous viscosity of the medium is set to $10^{25} \mathrm{Pas}$, which the maximum viscosity will not exceed. From the variation in friction angle $\left(0\right.$ to $\left.30^{\circ}\right)$ and lithostatic pressure $(0-270 \mathrm{MPa})$, together with the background strain rate, an estimate for the initial viscosity can be made $\left(1.7-8.5 \times 10^{22} \mathrm{Pas}\right)$.

$40 \times 10 \mathrm{~km}$ domain is set to free slip and the top boundary is stress free (material is free to flow in or out). Other domain characteristics and material parameters are given in Table 4.

The angle of internal friction $\phi$ (Eq. 8) is varied from 0 to $30^{\circ}$ to test the pressure dependency of the implemented plasticity criterion. It is expected that the resultant shear band angle $\theta$ varies with the internal friction angle. Shear band angles are automatically computed from the location of the maximum Frobenius norm of the strain rate $\sqrt{\dot{\epsilon}: \dot{\epsilon}}$ at $x=$ $17.4 \mathrm{~km}, x=19.4 \mathrm{~km}, x=20.6 \mathrm{~km}$ and $x=22.6 \mathrm{~km}$ (Kaus, 2010).

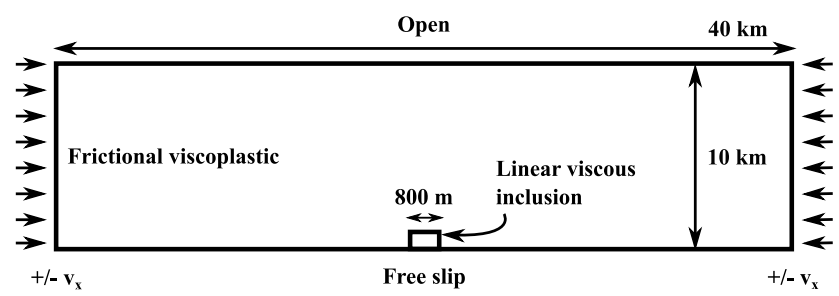

Figure 4. The brick benchmark model setup after Kaus (2010): a rectangular domain with a prescribed inward or outward horizontal component of velocity on the vertical boundaries (the vertical component is left free). The upper boundary is open, while the bottom boundary is free slip. A small viscous inclusion of $800 \times 400 \mathrm{~m}$ is placed at the bottom of the domain.

\subsubsection{Model results compared to the theoretical solution}

Figure 5 depicts the measured shear band angle versus the supplied internal friction angle for 21 runs in both the compressional and tensional regime. The constant and uniform elemental resolution of the runs varies from $256 \times 64$ to $1024 \times 256$ elements. Lower-resolution runs were performed, but do not resolve the viscous inclusion well $(\leq$ two elements) and are not shown (see instead Fig. 12 of Kaus, 2010). We monitor the residual as a measure of convergence, but the maximum number of nonlinear iterations (NIs; see Sect. 2.1.2) is fixed at 1000. The red symbols in Fig. 5 indicate runs for which the residual did not drop below the convergence criterion $\epsilon_{\mathrm{u}}=10^{-4}$ after 1000 iterations, as is evident from the corresponding red lines in Fig. 6. In fact, the higher the internal friction angle, the more iterations are needed to reach a particular residual tolerance, and Fig. 6 also shows that higher internal friction angle runs stall at higher residuals. This coincides with a greater deviation from the theoretical Coulomb solution. Note that in these higher angle runs multiple shear bands are generated and an asymmetry between the right and left shears develops, as shown in Fig. 7. The spurious shear bands can occur mainly at the top of the domain, as several curved pieces forming one shear band or as complete additional shears. Despite these difficulties, there is a clear trend of measured angles verging from Arthur to Coulomb angles for an increasing resolution. For example, the average deviation from the theoretical Coulomb angle decreases from 2.8 to $0.8^{\circ}$ in extension when going from a resolution of $256 \times 64$ elements to $1024 \times 256$ elements.

To estimate the effect of adaptive mesh refinement on the shear band angles, we ran additional tests with $3 \times 333$ nonlinear iterations at increasing refinement levels, with refinement based on gradients in the velocity, viscosity or strain rate and different fractions of cells that are refined. These simulations indicate a maximal variation of $5^{\circ}$ in shear band angle compared to results for a uniform mesh of $512 \times 128$ elements. 


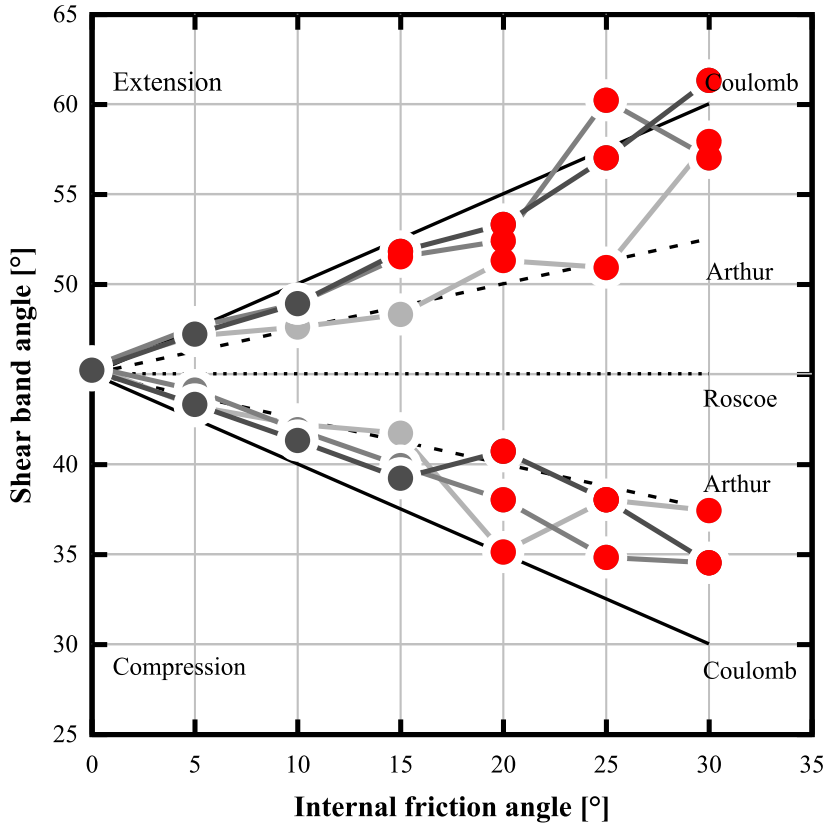

Figure 5. Measured shear band angle versus angle of internal friction for models in tension and compression. Resolution runs from $256 \times 64$ (light grey line), to $512 \times 128$ (grey) to $1024 \times 256$ elements (dark grey). All models were run for 1000 NIs; red symbol runs correspond to the red line runs in Fig. 6. The black lines represent the theoretical angles of Coulomb (solid), Arthur (dashed) and Roscoe (dotted). We have corrected one of the automated shear band angle measurements manually - that of the $1024 \times 256$ element extension case with $\phi=25^{\circ}-$ because it was computed using two different shear bands.

Varying the initial viscosity of the viscoplastic medium from $\mu_{\min }$ to $\mu_{\max }$ for a uniform mesh of $512 \times 128$ elements leads to the same shear band angles for well-behaved residual runs (see black lines in Fig. 6), while for higher internal angle of friction runs, a variation of maximally $3^{\circ}$ is found.

\subsubsection{Discussion}

Testing the pressure dependency of our plasticity formulation with the brick benchmark, shear band angles were found to increase with internal friction angle $\phi$ as expected, almost all falling within the theoretical values of Arthur and Coulomb. Moreover, with increasing mesh resolution, the angles approach the Coulomb theoretical angle $\theta=45 \pm \frac{\phi}{2}$ and the variation in error with respect to Coulomb angles decreases. This tendency towards Coulomb angles for higher mesh resolution was also reported by Lemiale et al. (2008), Kaus (2010) and Buiter (2012) because at higher resolution the viscous inclusion is better resolved. Kaus finds that at least 10 to 20 elements are required horizontally within the inclusion to obtain Coulomb angles. This corresponds to our two highest resolutions. Choi and Petersen (2015) recently showed that

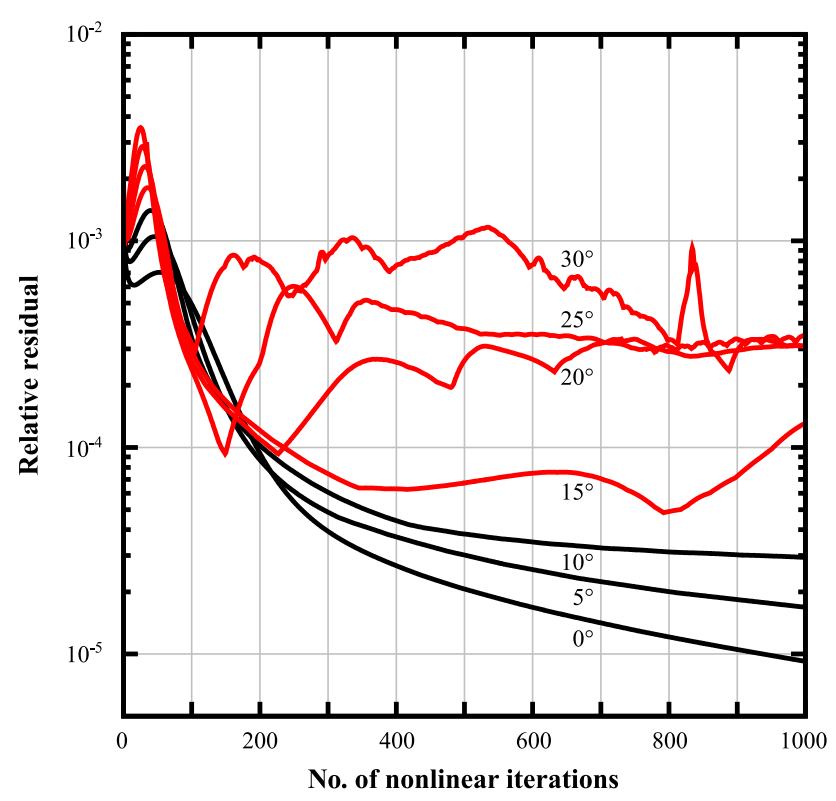

Figure 6. Measured velocity residual $\left(\epsilon_{u}=\frac{\left\|U_{i}-U_{i-i}\right\|_{\text {sup }}}{\left\|U_{i-1}\right\|_{\text {sup }}}\right.$ with $U$ the velocity solution; van den Berg et al., 1993; Kaus, 2010) versus the number of nonlinear iterations for models of extension. Elemental resolution is $512 \times 128$ elements. Black lines represent runs with well-behaved convergence.
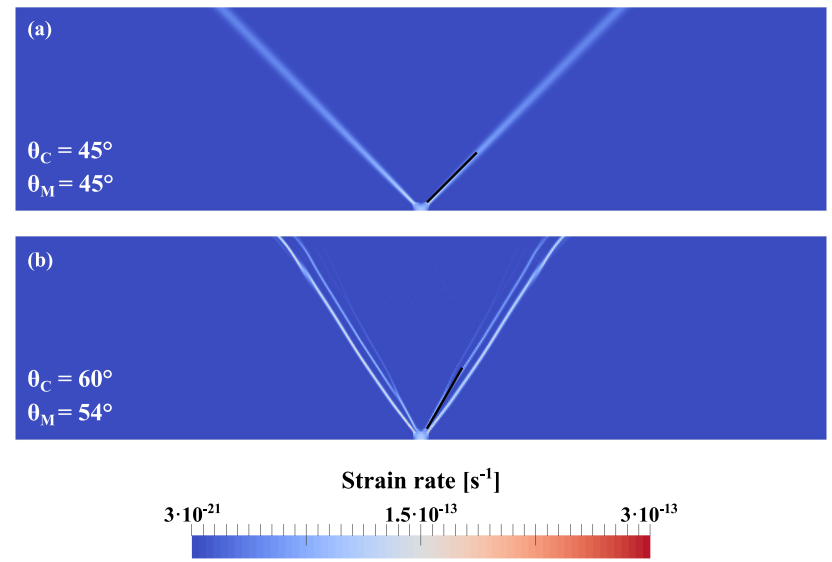

Figure 7. Strain rate norm fields for (a) $\phi=0^{\circ}$ and (b) $\phi=30^{\circ}$ for a $512 \times 128$ elemental resolution. The models were run in extension for 1000 NIs. Black lines indicate the theoretical Coulomb angle $\theta_{\mathrm{C}}$. Measured shear band angles $\theta_{\mathrm{M}}$ are also given.

consistent Coulomb angles can be achieved by an (initially) associated flow law (where $\phi=\psi$ ).

Interestingly, internal angles of friction larger than $15-20^{\circ}$ lead to irregular convergence behavior that stalls at higher relative residuals; these runs also show shear band angles further away from the theoretical Coulomb angle and multiple additional shears. These additional shears do often coincide with the theoretical angle; see for instance Fig. 7b. Why these latter shears are not dominant (highest strain rate) would 


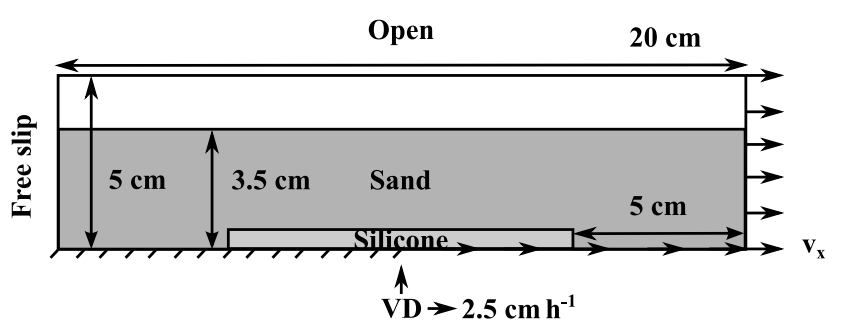

Figure 8. The sandbox experiment setup after Buiter et al. (2006). VD represents the velocity discontinuity moving at the same speed as is prescribed on the right and bottom boundary. Left of the VD, the bottom boundary is no slip. The left vertical boundary is set to free slip, while the top is open. The silicone layer measures $10 \times$ $0.5 \mathrm{~cm}$.

require further investigation. Note that the models of Kaus (2010) also show multiple shear bands and that these spurious bands and stalling of convergence are shown to be the result of the dynamic pressure dependence of the DruckerPrager yield criterion by Spiegelman et al. (2016).

However, we have shown that we consistently obtain shear band angles between Arthur and Coulomb theoretical angles at sufficient resolution and that these angles verge to Coulomb angles with increasing resolution. This happens despite the fact that our implementation is relatively basic: it does not include softening of cohesion or of the internal angle of friction as in Kaus (2010) and Buiter (2012), nor does it have a sophisticated guess of the initial stress state (Lemiale et al., 2008) or an incremental build-up of the prescribed boundary velocity (Kaus, 2010).

\subsection{The sandbox extension experiment}

Buiter et al. (2006) compared numerical and analog models of shortening and extension. We reproduce the numerical sandbox extension experiment, which was originally run with six different numerical codes and compared to the analog results described in Schreurs et al. (2006). This time-dependent experiment has previously been repeated by Thieulot (2011) and - in a symmetrical version - by Gerya et al. (2013).

\subsubsection{Model setup}

The analog sandbox (Buiter et al., 2006) consists of a basal layer of weak, viscous silicone overlain by brittle sand. The sand is extended by the movement of the right vertical wall and the connected basal plate extending from the wall to, initially, the center of the domain. We model this setup with three compositional fields (Fig. 8): (1) a viscous basal layer, (2) an overlying Drucker-Prager dynamic pressuredependent plastic sand layer and (3) a low-viscous sticky-air layer (Crameri et al., 2012) on top. Extension is driven by a prescribed horizontal velocity on the right vertical boundary and the right half of the lower boundary, mimicking the effect
Table 5. The sandbox experiment model parameters.

\begin{tabular}{ll}
\hline Parameter & Value (unit) \\
\hline Domain width $L_{x}$ & $20 \mathrm{~cm}$ \\
Domain height & $5 \mathrm{~cm}$ \\
Courant-Friedrichs-Lewy (CFL) number & 0.5 \\
Element size & $6.25 \times 6.25-0.39 \times 0.39 \mathrm{~mm}$ \\
Applied horizontal velocity $v_{x}$ & $2.5 \mathrm{~cm} \mathrm{~h}^{-1}$ \\
Gravity acceleration & $9.81 \mathrm{~m} \mathrm{~s}^{-2}$ \\
Reference viscosity $\mu_{\text {ref }}$ & $10^{7} \mathrm{~Pa} \mathrm{~s}$ \\
Initial effective strain rate $\dot{\epsilon}_{\text {init }}$ & $10^{-6} \mathrm{~s}^{-1}$ \\
Effective viscosity $\mu_{\mathrm{eff}}$ & Eq. $(12)$ \\
Minimum viscosity $\mu_{\min }$ & $10^{2} \mathrm{~Pa} \mathrm{~s}$ \\
Maximum viscosity $\mu_{\mathrm{max}}$ & $10^{9} \mathrm{~Pa} \mathrm{~s}$ \\
Viscosity capping $\mu_{\mathrm{eff}}$ & $\mathrm{Eq} .(13)$ \\
No. of NIs per time step $\left(t_{0} ; \mathrm{rest}\right)$ & $100 ; 20$ \\
Stokes solver tolerance & $10^{-6}$ \\
Model end time & $3100 \mathrm{~s}$ \\
No. of cores & 24 \\
DOF/core & $\sim 32000$ \\
No. of time steps & 227 \\
Wall time & $41 \mathrm{~h}$ \\
\hline
\end{tabular}

Sticky air

\begin{tabular}{ll}
\hline $\begin{array}{l}\text { Constant density } \rho \\
\text { Linear viscous viscosity } \mu\end{array}$ & $\begin{array}{l}10 \mathrm{~kg} \mathrm{~m}^{-3} \\
10^{2} \mathrm{Pas}\end{array}$ \\
\hline Sand & \\
\hline Constant density $\rho$ & $1560 \mathrm{~kg} \mathrm{~m}^{-3}$ \\
Linear viscous viscosity $\mu$ & $10^{13} \mathrm{Pas}$ \\
Cohesion $C$ & $10 \mathrm{~Pa}$ \\
Angle of internal friction $\phi$ & $36^{\circ}$
\end{tabular}

Angle of internal friction $\phi$

Silicon

Constant density $\rho \quad 965 \mathrm{~kg} \mathrm{~m}^{-3}$

Linear viscous viscosity $\mu \quad 5 \times 10^{4} \mathrm{Pas}$

Parameters are on a sandbox scale, as they are used in the model. An estimate for the initial strain rate can be made from the boundary conditions $\dot{\epsilon}_{\text {init }} \approx \frac{\Delta v_{x}}{L_{x}}=\frac{6.94 \times 10^{-6}}{0.2}=3.47 \times 10^{-5} \mathrm{~s}^{-1}$ and should not exceed the maximum strain rate estimate $\frac{\Delta v_{x}}{\Delta x}=\frac{6.94 \times 10^{-6}}{0.00039}=1.78 \times 10^{-2} \mathrm{~s}^{-1}$. The maximum strain rate can be used together with the minimum yield strength (zero pressure) to compute the minimum viscosity of the sand of about $227 \mathrm{Pas}$.

of the moving basal sheet. Basal friction is not taken into account. This approach is appropriate since Buiter et al. (2006) have shown that the nature of the basal contact is less important than the interaction of the velocity discontinuity (VD in Fig. 8) and the silicone. The rest of the bottom boundary has zero velocity (without smoothing of the velocity discontinuity) and this no-slip area increases as the velocity discontinuity moves to the right of the domain. The left boundary is free slip and the top boundary is open. Adaptive mesh refinement (AMR) is applied based on the effective strain rate field or on viscosity and density to obtain a maximum local refinement of $0.39 \times 0.39 \mathrm{~mm}$ along the shear bands (Fig. 10). The model is run until $2 \mathrm{~cm}$ of extension has occurred, equalling $2880 \mathrm{~s}$ of model time. Material properties and other model parameters are listed in Table 5. 


\subsubsection{Model results}

The results for 1 and $2 \mathrm{~cm}$ of extension of the sandbox are presented in Fig. 9. The evolution of the model closely resembles what was found by Buiter et al. (2006). The initially symmetric system forms two conjugate shear zones stemming from the velocity discontinuity imposed by the velocity boundary conditions. With ongoing extension, the silicone layer distributes deformation and the shear bands spread to the edges of the layer. After 1 and $2 \mathrm{~cm}$ of extension, the angle of the shear bands left and right of the velocity discontinuity (see Fig. 9d) measure left $\sim 51$, right $\sim 62$ and left $\sim 54$, right $\sim 60^{\circ}$. With time the system becomes more and more asymmetric (compare left and right column of Fig. 9). The left side of the domain is at rest, while the outer right footwall moves at the prescribed velocity and we observe that the sticky air properly accommodates the movement of the sand.

The viscosity field (Fig. 9h) is very irregular and displays sharp gradients up to 7 orders of magnitude. Figure 10 demonstrates viscosity- and density-based AMR: refinement is localized in the low-viscosity shear bands, following the evolution of deformation. Through AMR, the total (velocity, pressure, temperature, composition) number of degrees of freedom (DOFs) is limited to on average $\sim 475000 \mathrm{DOFs}$, instead of the $\sim 1383000$ DOFs $(\sim 527000$ velocity DOFs $)$ for a uniform resolution, thus decreasing the required computational resources by half (for the same number of cores).

\subsubsection{Discussion}

The evolution of the numerical sandbox model - a model with AMR, high viscosity contrasts, large deformation and complex boundary conditions - compares well with those shown in Buiter et al. (2006) and Thieulot (2011). Although the shear band angles to the right of the velocity discontinuity of 62 and $60^{\circ}$ after 1 and $2 \mathrm{~cm}$ of deformation fall just outside the ranges found by Buiter et al. (2006) and Thieulot (2011) of 45-55 and $45-53^{\circ}$, respectively, they lie within the theoretical Arthur-Coulomb angles of 54-63 ${ }^{\circ}$ for a friction angle of $36^{\circ}$ (Vermeer, 1990; see also Sect. 3.2). Even when considering that the codes in Buiter et al. (2006) add strain softening by decreasing the friction angle from 36 to $31^{\circ}$, for which the range of Arthur-Coulomb angles would be $52.75-60.50^{\circ}$, their measured angles lie mostly below the Arthur angle. In the previous section, we demonstrated that our shear band angles fall within the Arthur-Coulomb range and verge towards Coulomb angles with increasing mesh resolution. Differences in the measured angle of shear bands are therefore not surprising. A lower-resolution run (maximum of $0.78 \mathrm{~mm}$ resolution, not shown) results in angles to the right of the discontinuity of 60 and $55^{\circ}$.

Similar to Buiter et al. (2006), Thieulot (2011) and Buiter (2012), we observe an increase in the number of shear bands with resolution as well as a decrease in their width. As ex- plained by Spiegelman et al. (2016), this lack of internal length scale is caused by the singularities in strain rate and pressure deriving from the model setup (e.g., sharp corners of the silicon layer and the discontinuous velocity boundary condition) that are resolved better at higher resolutions, thereby decreasing shear band width.

\subsection{The slab detachment benchmark}

Slab detachment, or break-off, in the final stage of subduction is often invoked to explain geophysical and geological observations such as tomographic images of slab remnants and exhumed ultra-high-pressure rocks (see for example Wortel and Spakman (2000) and references therein). Due to the increased interest in the process of slab tearing, it has recently been the subject of several numerical modeling studies (e.g., Gerya et al., 2004; Andrews and Billen, 2009; Burkett and Billen, 2009, 2010; van Hunen and Allen, 2011; Duretz et al., 2012, 2014). Numerical modeling of slab detachment is computationally challenging due to the mesh-resolution dependency of the strain (van Hunen and Allen, 2011) and the gradual decrease in monitoring particle density, the gradual overlapping of level sets (Hillebrand et al., 2014) or the gradual thinning of compositional fields (as is the case here) in the detachment area. Here we test ASPECT with the slab detachment model of Schmalholz (2011), which considers a simplified geometry of detachment by viscous necking of a vertical lithospheric slab of nonlinear rheology in a linearly or nonlinearly viscous mantle. It has been extended to 3-D by von Tscharner et al. (2014).

\subsubsection{Model setup}

The 2-D detachment model geometry is outlined in Fig. 11; both the lithosphere and the mantle are represented by a compositional field. Schmalholz (2011) prescribes a nonlinear viscosity in the subducting lithosphere given by

$\eta_{\mathrm{L}}=\eta_{0} \dot{\epsilon}_{e}^{\left(\frac{1}{n}-1\right)}$

where $\eta_{0}=4.75 \times 10^{11} \mathrm{Pas}^{\frac{1}{n}}$ and $n=4$. Conversion to Eq. (5) results in the parameters listed in Table 6. Here we only reproduce the constant mantle viscosity case of Schmalholz (2011), with $\mu_{\text {mantle }}=10^{21}$ Pas. We use a set of 20 tracers placed on the outline of the slab to track the width and depth of necking. The necking width and depth, as well as time, are normalized by the initial slab width of $80 \mathrm{~km}$ and the characteristic time $t_{\mathrm{c}}=7.1158 \times 10^{14} \mathrm{~s}$, respectively (Schmalholz, 2011).

\subsubsection{Results and comparison}

The evolution of the detachment model is shown in Fig. 12: after about $20 \mathrm{Myr}$, the slab is fully necked and detached. Although a thin line of lithosphere composition is still visible, its value is less than 0.5 and thus the infinite norm ig- 

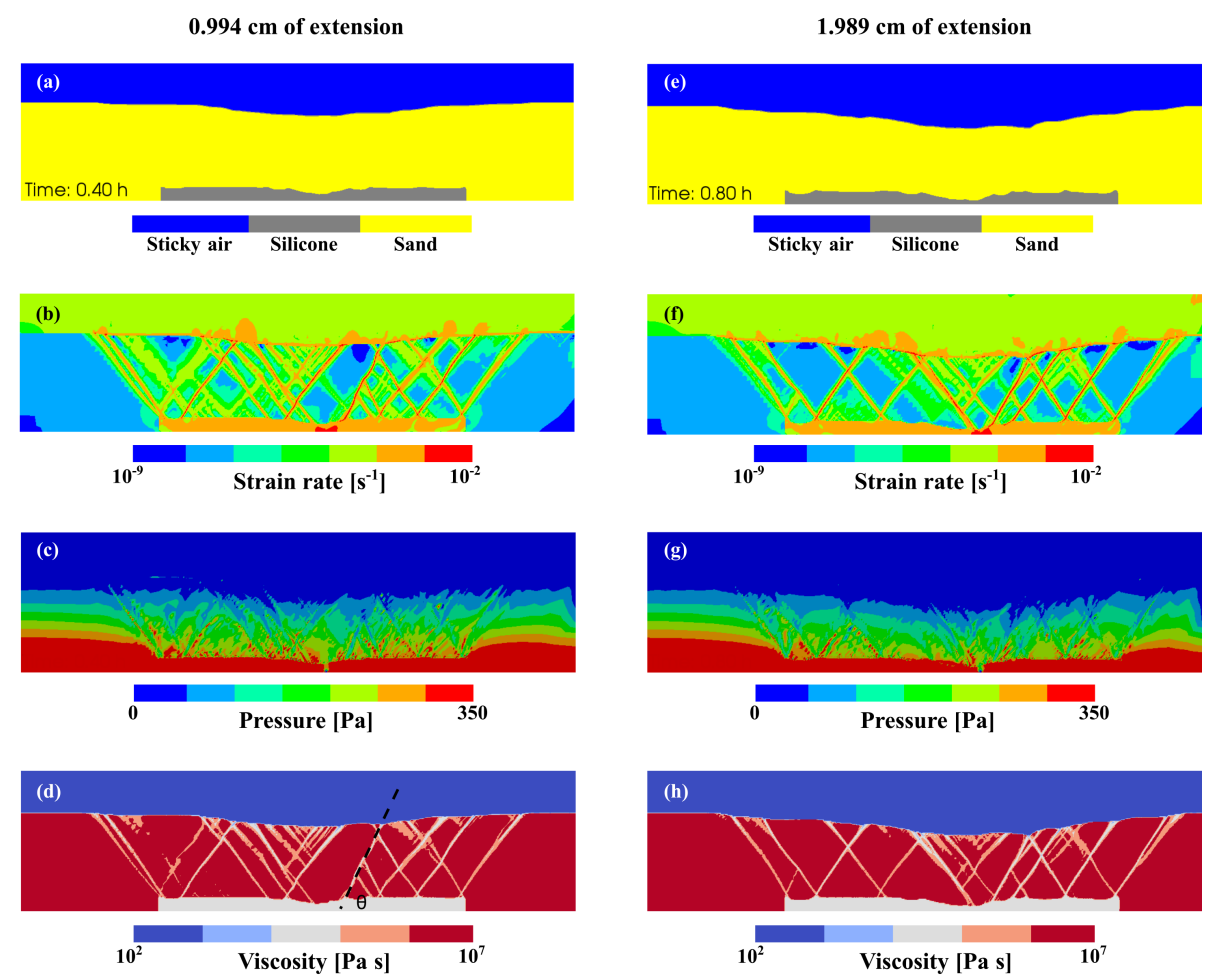

Figure 9. Results after $\sim 1$ and $\sim 2 \mathrm{~cm}$ of extension of the numerical sandbox. (a, e) The three compositional fields. Note the asymmetric depression of the sand surface. $(\mathbf{b}, \mathbf{f})$ Frobenius norm of the strain rate $\sqrt{\dot{\epsilon}: \dot{\epsilon}} .(\mathbf{c}, \mathbf{g})$ Total pressure field. (d, h) Viscosity field.

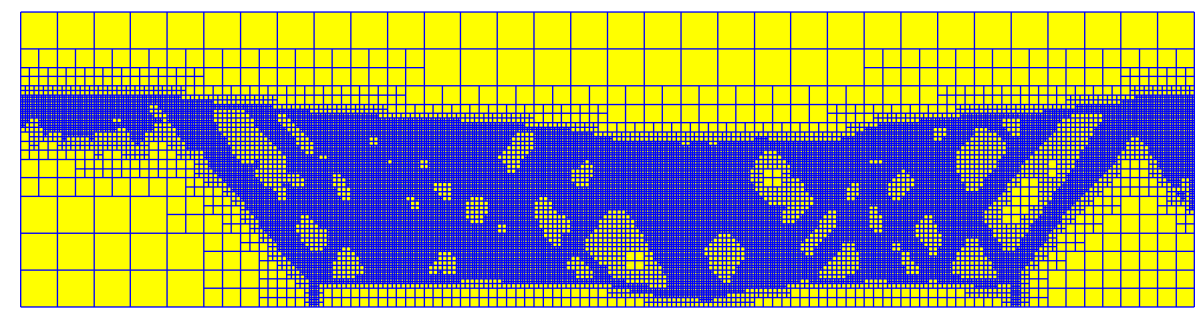

Figure 10. Numerical grid after $\sim 2 \mathrm{~cm}$ of extension of the numerical sandbox. Adaptive mesh refinement and coarsening based on the viscosity and density leads to a minimum resolution of $6.25 \times 6.25 \mathrm{~mm}$ and a maximum resolution of $0.39 \times 0.39 \mathrm{~mm}$.

nores this contribution to the viscosity, allowing for full detachment. Upon detachment, slab pull is removed and thus viscosity reaches $\mu_{\max }$ throughout the remaining lithosphere (Fig. 12c and d).

From comparison of the red and black lines in Fig. 13, it can be seen that the width of the necked zone through time agrees very well with the results of Schmalholz (2011). Only after $t=0.8$, do our results start to deviate due to our use of tracers for measuring the necking width. The two other lines illustrate the effect of using harmonic averaging for the compositional fields' contribution to viscosity (blue line) or for averaging the viscosity over the elements (yellow line): although these averaging methods reduce the wall time by a factor of 3 and 2, respectively, they also result in much faster necking. This agrees with the findings in Appendix A.

\subsubsection{Discussion}

The first three benchmarks focused on plastic rheologies. The detachment benchmark involves modeling of a highly nonlinear, power-law viscosity, which is often used in subduction modeling. Our observed model evolution compares well with that of Schmalholz (2011) and other codes (Hillebrand et al., 2014). It also demonstrates the effective splitting of a compositional field into two bodies and how the rheology interacts with the compositional fields through localization of deformation at the slab hinge. It should be noted that the particular geometry of the slab with its sharp corners results in a mesh dependence of the solution. Differences in model evolution can also arise from the particular viscosity and material averaging method applied. 


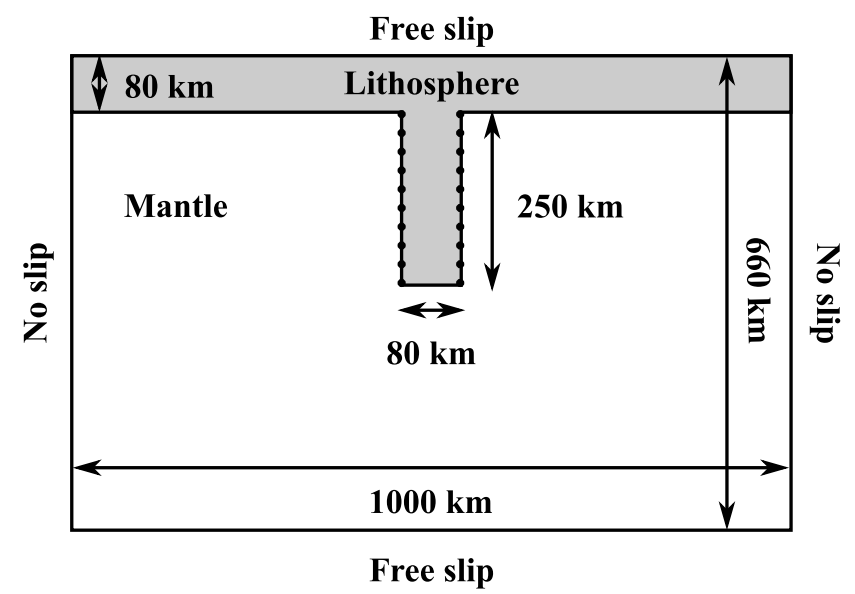

Figure 11. The detachment benchmark model setup of Schmalholz (2011): a symmetric system of nonlinear viscous lithosphere (Eq. 19) with a vertical slab extending into a linear viscous mantle. The top and bottom boundaries are free slip, while the vertical boundaries are no slip. Along the outline of the slab are placed 20 passive tracers to track the necking of the slab.
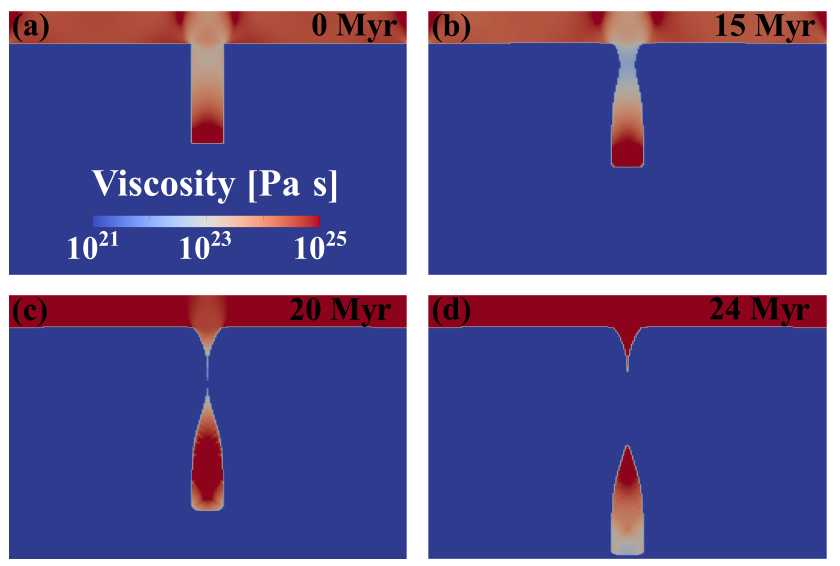

Figure 12. Detachment benchmark model evolution showing the viscosity field over time. After about $20 \mathrm{Myr}$, necking is complete and the remaining lithosphere reaches a high, uniform viscosity.

\section{Viscoplastic subduction models}

Lastly, we consider a geodynamical application of the viscoplastic rheology implemented: the spatiotemporal evolution of 3-D subduction. So far, no ASPECT applications to 2-D or 3-D regional subduction have been published. To demonstrate ASPECT's promise in this field, here we present 3-D models of free-plate intraoceanic subduction. Recent 3-D subduction models have been applied in the study of along-strike effects such as oblique convergence (Malatesta et al., 2013), toroidal flow (Schellart and Moresi, 2013), varying lithospheric structure (Mason et al., 2010; van Hunen and Allen, 2011; Capitanio and Faccenda, 2012; Duretz et al., 2014), slab width (Stegman et al., 2006, 2010;
Table 6. The detachment benchmark model parameters.

\begin{tabular}{|c|c|}
\hline Parameter & Value (unit) \\
\hline Domain width & $1000 \mathrm{~km}$ \\
\hline Domain height & $660 \mathrm{~km}$ \\
\hline CFL number & 1.0 \\
\hline Element size & $15.63 \times 10.31-3.91 \times 2.58 \mathrm{~km}$ \\
\hline Gravity acceleration & $9.81 \mathrm{~m} \mathrm{~s}^{-2}$ \\
\hline Reference viscosity $\mu_{\text {ref }}$ & $3 \times 10^{22} \mathrm{Pas}$ \\
\hline Minimum viscosity $\mu_{\min }$ & $10^{21} \mathrm{Pas}$ \\
\hline Maximum viscosity $\mu_{\max }$ & $10^{25} \mathrm{Pas}$ \\
\hline Viscosity capping $\mu_{\text {eff }}$ & Eq. (13) \\
\hline Max. no. of NIs per time step & 50 \\
\hline Max. no. of cheap Stokes solves & 200 \\
\hline Stokes solver tolerance & $10^{-5}$ \\
\hline Model end time & $25 \mathrm{Myr}$ \\
\hline Temperature polynomial degree & 1 \\
\hline No. of cores & 28 \\
\hline DOF/core & $\sim 16300$ \\
\hline No. of time steps & 289 \\
\hline Wall time & $4 \mathrm{~h}$ \\
\hline \multicolumn{2}{|l|}{ Lithosphere } \\
\hline Constant density $\rho$ & $3300 \mathrm{~kg} \mathrm{~m}^{-3}$ \\
\hline Activation volume $V$ & $0 \mathrm{~m}^{3} \mathrm{~mol}^{-1}$ \\
\hline Activation energy $Q$ & $0 \mathrm{~J} \mathrm{~mol}^{-1}$ \\
\hline Stress exponent $n$ & 4 \\
\hline Prefactor $B$ & $1.23 \times 10^{-48} \mathrm{~Pa}^{-\mathrm{n}} \mathrm{s}^{-1}$ \\
\hline Initial viscosity $\mu_{\text {init }}$ & $2 \times 10^{23} \mathrm{Pas}$ \\
\hline \multicolumn{2}{|l|}{ Mantle } \\
\hline Constant density $\rho$ & $3150 \mathrm{~kg} \mathrm{~m}^{-3}$ \\
\hline Activation volume $V$ & $0 \mathrm{~m}^{3} \mathrm{~mol}^{-1}$ \\
\hline Activation energy $Q$ & $0 \mathrm{~J} \mathrm{~mol}^{-1}$ \\
\hline Stress exponent $n$ & 1 \\
\hline Prefactor $B$ & $5.0 \times 10^{-22} \mathrm{~Pa}^{-\mathrm{n}} \mathrm{s}^{-1}$ \\
\hline Initial viscosity $\mu_{\text {init }}$ & $10^{21} \mathrm{Pas}$ \\
\hline
\end{tabular}

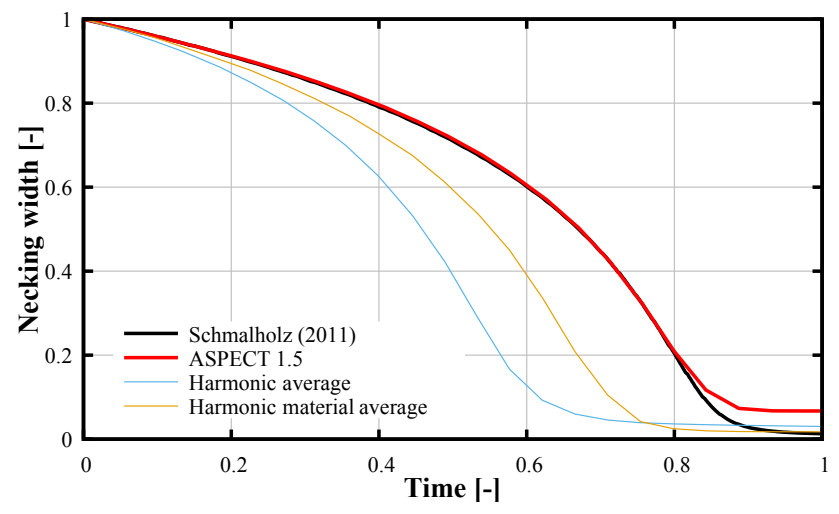

Figure 13. Nondimensional necking width versus time for ASPECT and Schmalholz (2011). The ASPECT necking width is calculated from the 20 tracer positions. Because the tracers above the necking zone no longer move after detachment, the thus-calculated width stagnates after $t \simeq 0.9$. 
Schellart et al., 2007) and the presence of lateral plates (Yamato et al., 2009). Four-dimensional (3-D plus time) modeling allows us to more realistically investigate the generics of subduction (e.g., Crameri and Tackley, 2014; Chertova et al., 2014b) as well as very specific regional problems (e.g., Capitanio and Replumaz, 2013; Chertova et al., 2014a; Sternai et al., 2014).

\subsection{Model setup}

We discuss two models; the first is an adaptation of the freeplate model of Schellart and Moresi (2013), which considers no temperature effects and features constant viscosities except for a viscoplastic crustal layer. The second model is an extension of the first, where we add a temperature field and a viscosity dependent on temperature, pressure and strain rate, resulting in a nonlinear viscoplastic thermomechanically coupled system.

\subsubsection{Model 1}

The first model comprises two free plates: an overriding plate (OP) and a subducting plate (SP) (see Fig. 14). The SP is made up of a crustal layer of non-frictional (von Mises) viscoplastic rheology and a mantle lithospheric layer of constant viscosity (see Table 8 for actual values). The tip of the SP extends into the mantle for $200 \mathrm{~km}$. The OP is of one composition and has a constant viscosity, as does the surrounding mantle. These four compositions are each represented by a compositional field.

\subsubsection{Model 2}

The second model augments the first with an adjacent plate (AP) separated from the other plates by a $20 \mathrm{~km}$ thick weak zone (WZ). The SP and OP are extended and their thickness is no longer uniform, but based on the temperature field, as if they originate from ridges situated at the left and right vertical domain boundaries. The initial temperature distribution (Fig. 15) in the plates is computed according to the age-based plate cooling model, for a mantle temperature $T_{\mathrm{a}}$ of $1593 \mathrm{~K}$ and surface temperature $T_{0}=293 \mathrm{~K}$ (Eq. 4.2.24 of Schubert et al., 2001; $\kappa=10^{-6} \mathrm{~m}^{2} \mathrm{~s}^{-1}$ ). Thickness of the plate is defined at the temperature $T$ for which $\frac{T_{\mathrm{a}}-T}{T_{\mathrm{a}}-T_{0}}=0.1$. The maximum thickness of the plate (for time to infinity) is set to $125 \mathrm{~km}$, based on Schubert et al. (2001). At the trench, both plates have the same thickness as in model 1 . The adjacent plate (AP) has a fixed thickness of $100 \mathrm{~km}$ for an age of $\sim 60$ Myr. From a depth of $125 \mathrm{~km}$, a linear temperature increase is prescribed everywhere to a bottom temperature of $1771 \mathrm{~K}$. The mantle and overriding plate compositions are of nonlinear rheology, with which model 2 differs strongly from model 1 . The specific rheological parameters for diffusion and dislocation creep and Drucker-Prager plasticity can be found in Table 8 and the representative viscosity profiles in Fig. 16.
Table 7. Three-dimensional subduction model parameters.

\begin{tabular}{|c|c|}
\hline Parameter & Value (unit) \\
\hline Domain length & $4000 \mathrm{~km}$ \\
\hline Domain width & $800 \mathrm{~km}$ \\
\hline Domain height & $660 \mathrm{~km}$ \\
\hline Gravitational acceleration & $9.81 \mathrm{~m} \mathrm{~s}^{-2}$ \\
\hline \multicolumn{2}{|l|}{ Model 1} \\
\hline Effective viscosity $\mu_{\mathrm{eff}}^{\mathrm{vp}}$ & Eq. (11) \\
\hline Minimum viscosity $\mu_{\min }$ & $10^{19} \mathrm{Pas}$ \\
\hline Maximum viscosity $\mu_{\max }$ & $1.57 \times 10^{23} \mathrm{Pas}$ \\
\hline Viscosity capping $\mu_{\text {eff }}$ & Eq. (13) \\
\hline Element size & $\begin{array}{l}50.00 \times 50.00 \times 41.25 \\
3.13 \times 3.13 \times 2.58 \mathrm{~km}\end{array}$ \\
\hline Max. no. of nonlinear iterations NIs & 100 \\
\hline Stokes solver tolerance & $10^{-5}$ \\
\hline No. of cores & 104 \\
\hline DOFs/core & $\sim 65000$ \\
\hline Wall time & 2.5 weeks \\
\hline Model run time & $40 \mathrm{Myr}$ \\
\hline No. of time steps & 1075 \\
\hline \multicolumn{2}{|l|}{ Model 2} \\
\hline Reference viscosity $\mu_{\text {ref }}$ & $10^{21} \mathrm{Pas}$ \\
\hline Effective viscosity $\mu_{\mathrm{eff}}^{\mathrm{vp}}$ & Eq. (12) \\
\hline Minimum viscosity $\mu_{\min }$ & $10^{19} \mathrm{Pas}$ \\
\hline Maximum viscosity $\mu_{\max }$ & $10^{24} \mathrm{Pas}$ \\
\hline Viscosity capping $\mu_{\mathrm{eff}}$ & Eq. (14) \\
\hline Material averaging & logarithmic \\
\hline Thermal conductivity $k$ & $2.0 \mathrm{~W} \mathrm{~m}^{-1} \mathrm{~K}^{-1}$ \\
\hline Thermal expansivity $\alpha$ & $2.0 \times 10^{-5} \mathrm{~K}^{-1}$ \\
\hline Reference temperature $T_{0}$ & $293 \mathrm{~K}$ \\
\hline Element size & $\begin{array}{l}50.00 \times 50.00 \times 41.25 \\
6.25 \times 6.25 \times 5.16 \mathrm{~km}\end{array}$ \\
\hline Max. no. of nonlinear iterations NIs $\left(t_{0} ;\right.$ rest $)$ & $100 ; 10$ \\
\hline Stokes solver tolerance & $10^{-6}$ \\
\hline Relative residual tolerance & $5.0 \times 10^{-5}$ \\
\hline No. of cores & 260 \\
\hline DOFs/core & $\sim 132500$ \\
\hline Wall time & 6 weeks \\
\hline Model run time & $64 \mathrm{Myr}$ \\
\hline No. of time steps & 3100 \\
\hline
\end{tabular}

\subsection{Results}

\subsubsection{Model 1}

Figure 17 depicts the evolution of the subduction system of model 1 over time. The pull of the slab extending into the mantle results in a plastically weakened subduction fault zone through high strain rates. Although this allows for decoupling from the surface, mechanical coupling is strong enough for the OP to move towards the trench. There the OP thickens and a small portion of OP material is entrained with the slab. Within the first $\sim 7 \mathrm{Myr}$, the velocity of the plates steadily increases about 1 order of magnitude and reaches several centimeters per year. Similar to Schellart and Moresi (2013), poloidal and toroidal flow can be observed 

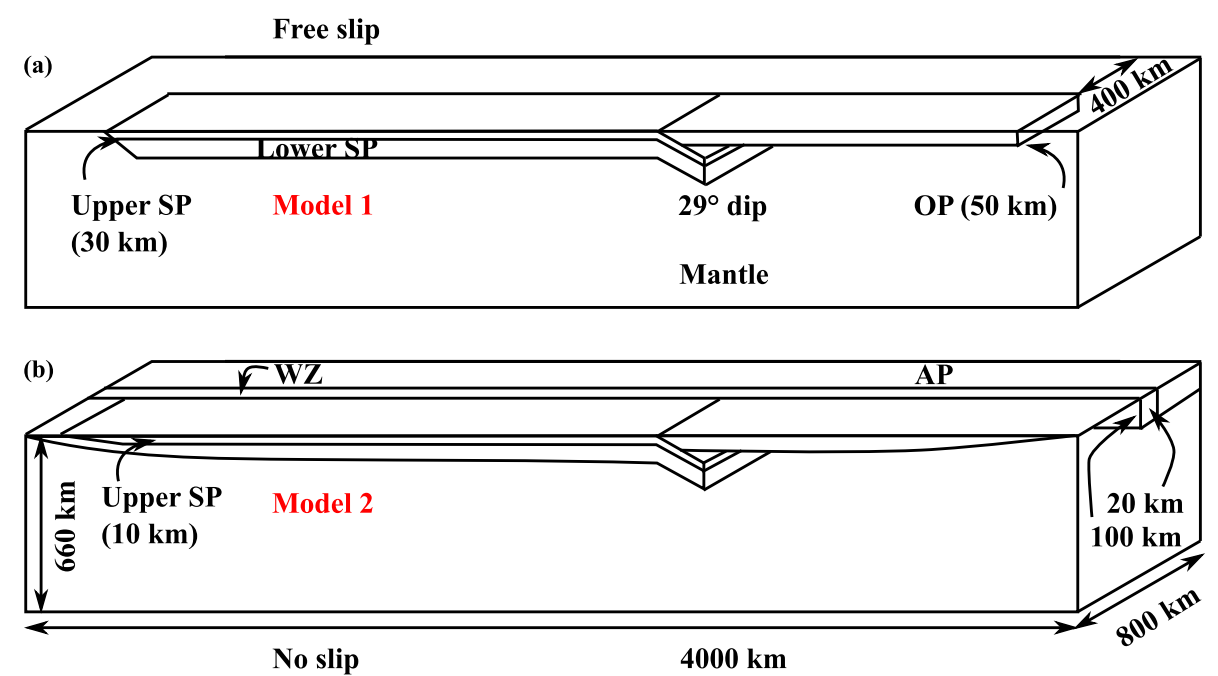

Figure 14. Three-dimensional subduction model setups (also, see Table 7). (a) Model 1: a free overriding plate (OP) and a subducting plate (SP) with a trench at $x=2400 \mathrm{~km}$. At start-up, the slab extends $200 \mathrm{~km}$ into the mantle (measured vertically) at an angle of $29^{\circ}$. The $100 \mathrm{~km}$ thick SP consists of two compositional layers, the OP of only one composition. All boundaries are free slip, except the no-slip bottom boundary. (b) Model 2: a 58.8 Myr old adjacent plate (AP) is added, separated from the OP and SP by a weak zone (WZ) of 20km width. The initial temperature distribution of the SP and OP is based on the plate cooling model dependent on age, which increases from the ridge situated at the left, respectively right, vertical domain boundary, up to an age of $16 \mathrm{Myr}$ for the OP and $60 \mathrm{Myr}$ for the SP, resulting in thicknesses of 50 and $100 \mathrm{~km}$ at the trench, respectively. An adiabat of $0.25 \mathrm{Kkm}^{-1}$ is prescribed in the mantle. The bottom temperature is fixed at $1728 \mathrm{~K}$, the top at $293 \mathrm{~K}$.

Table 8. Three-dimensional subduction model parameters (based on Hirth and Kohlstedt, 2003, and Ranalli, 1995).

\begin{tabular}{|c|c|c|c|c|c|c|c|}
\hline Parameter & Mantle & OP & Mantle SP & Crust SP & AP & $\mathrm{WZ}$ & Unit \\
\hline \multicolumn{8}{|l|}{ Model 1} \\
\hline Activation volume $V_{\mathrm{dl}}$ & 0.0 & 0.0 & 0.0 & 0.0 & & & $\mathrm{~m}^{3} \mathrm{~mol}^{-1}$ \\
\hline Activation energy $Q_{\mathrm{dl}}$ & 0.0 & 0.0 & 0.0 & 0.0 & & & $\mathrm{~J} \mathrm{~mol}^{-1}$ \\
\hline Stress exponent $n$ & 1.0 & 1.0 & 1.0 & 1.0 & & & - \\
\hline Prefactor $B_{\mathrm{dl}}$ & $2.12 \times 10^{-21}$ & $1.06 \times 10^{-23}$ & $3.03 \times 10^{-24}$ & $2.12 \times 10^{-24}$ & & & $\mathrm{~Pa}^{-\mathrm{n}} \mathrm{s}^{-1}$ \\
\hline Internal angle of friction $\phi$ & 0.0 & 0.0 & 0.0 & 0.0 & & & $\circ$ \\
\hline Cohesion $C$ & $1.0 \times 10^{15}$ & $1.0 \times 10^{15}$ & $1.0 \times 10^{15}$ & $2.0 \times 10^{7}$ & & & $\mathrm{~Pa}$ \\
\hline Initial viscosity $\mu_{\text {init }}$ & $1.57 \times 10^{20}$ & $3.14 \times 10^{22}$ & $4.71 \times 10^{22}$ & $1.57 \times 10^{23}$ & & & Pas \\
\hline Constant density $\rho$ & 3250 & 3250 & 3330 & 3330 & & & $\mathrm{~kg} \mathrm{~m}^{-3}$ \\
\hline \multicolumn{8}{|l|}{ Model 2} \\
\hline Activation volume $V_{\mathrm{df}}$ & $5.0 \times 10^{-6}$ & $6.0 \times 10^{-6}$ & $6.0 \times 10^{-6}$ & 0.0 & 0.0 & 0.0 & $\mathrm{~m}^{3} \mathrm{~mol}^{-1}$ \\
\hline Activation energy $Q_{\mathrm{df}}$ & $2.4 \times 10^{5}$ & $3.0 \times 10^{5}$ & $3.0 \times 10^{5}$ & 0.0 & 0.0 & 0.0 & $\mathrm{~J} \mathrm{~mol}^{-1}$ \\
\hline Prefactor $B_{\mathrm{df}}$ & $3.73 \times 10^{-14}$ & $6.08 \times 10^{-14}$ & $6.08 \times 10^{-14}$ & 0.0 & 0.0 & 0.0 & $\mathrm{~Pa}^{-\mathrm{n}} \mathrm{s}^{-1}$ \\
\hline Scaling factor $\beta_{\mathrm{df}}$ & 0.5 & 1.0 & 1.0 & 2.0 & 2.0 & 2.0 & - \\
\hline Activation volume $V_{\mathrm{dl}}$ & $15 \times 10^{-6}$ & $20 \times 10^{-6}$ & $20 \times 10^{-6}$ & 0.0 & 0.0 & 0.0 & $\mathrm{~m}^{3} \mathrm{~mol}^{-1}$ \\
\hline Activation energy $Q_{\mathrm{dl}}$ & $4.3 \times 10^{5}$ & $5.4 \times 10^{5}$ & $5.4 \times 10^{5}$ & 0.0 & 0.0 & 0.0 & $\mathrm{~J} \mathrm{~mol}^{-1}$ \\
\hline Prefactor $B_{\mathrm{dl}}$ & $3.91 \times 10^{-15}$ & $2.42 \times 10^{-16}$ & $2.42 \times 10^{-16}$ & $1.0 \times 10^{-19}$ & $1.0 \times 10^{-24}$ & $1.0 \times 10^{-21}$ & $\mathrm{~Pa}^{-\mathrm{n}} \mathrm{s}^{-1}$ \\
\hline Stress exponent $\mathrm{n}$ & 3.0 & 3.5 & 3.5 & 1.0 & 1.0 & 1.0 & - \\
\hline Scaling factor $\beta_{\mathrm{dl}}$ & 0.5 & 1.0 & 1.0 & 2.0 & 2.0 & 2.0 & - \\
\hline Internal angle of friction $\phi$ & 20 & 0.0 & 20 & 0.0 & 0.0 & 0.0 & $\circ$ \\
\hline Cohesion $C$ & $10^{6}$ & $10^{15}$ & $10^{6}$ & $10^{15}$ & $10^{15}$ & $10^{15}$ & $\mathrm{~Pa}$ \\
\hline Initial viscosity $\mu_{\text {init }}$ & $2.0 \times 10^{20}$ & $5.4 \times 10^{23}$ & $5.4 \times 10^{23}$ & $1.0 \times 10^{20}$ & $5.4 \times 10^{23}$ & $1.0 \times 10^{21}$ & Pas \\
\hline Specific heat $c_{\mathrm{p}}$ & 1250 & 1250 & 1250 & 750 & 1250 & 1250 & $\mathrm{~J} \mathrm{~kg}^{-1} \mathrm{~K}^{-1}$ \\
\hline Reference density $\rho_{0}$ & 3350 & 3350 & 3350 & 3150 & 3350 & 3350 & $\mathrm{~kg} \mathrm{~m}^{-3}$ \\
\hline
\end{tabular}

* For a fixed grain size of $0.01 \mathrm{~m}$ (Hirth and Kohlstedt, 2003), length of Burgers vector of $0.5 \mathrm{~nm}$ (Karato and Wu, 1993) and a shear modulus of $80 \mathrm{GPa}$ (Karato and Wu, 1993). 

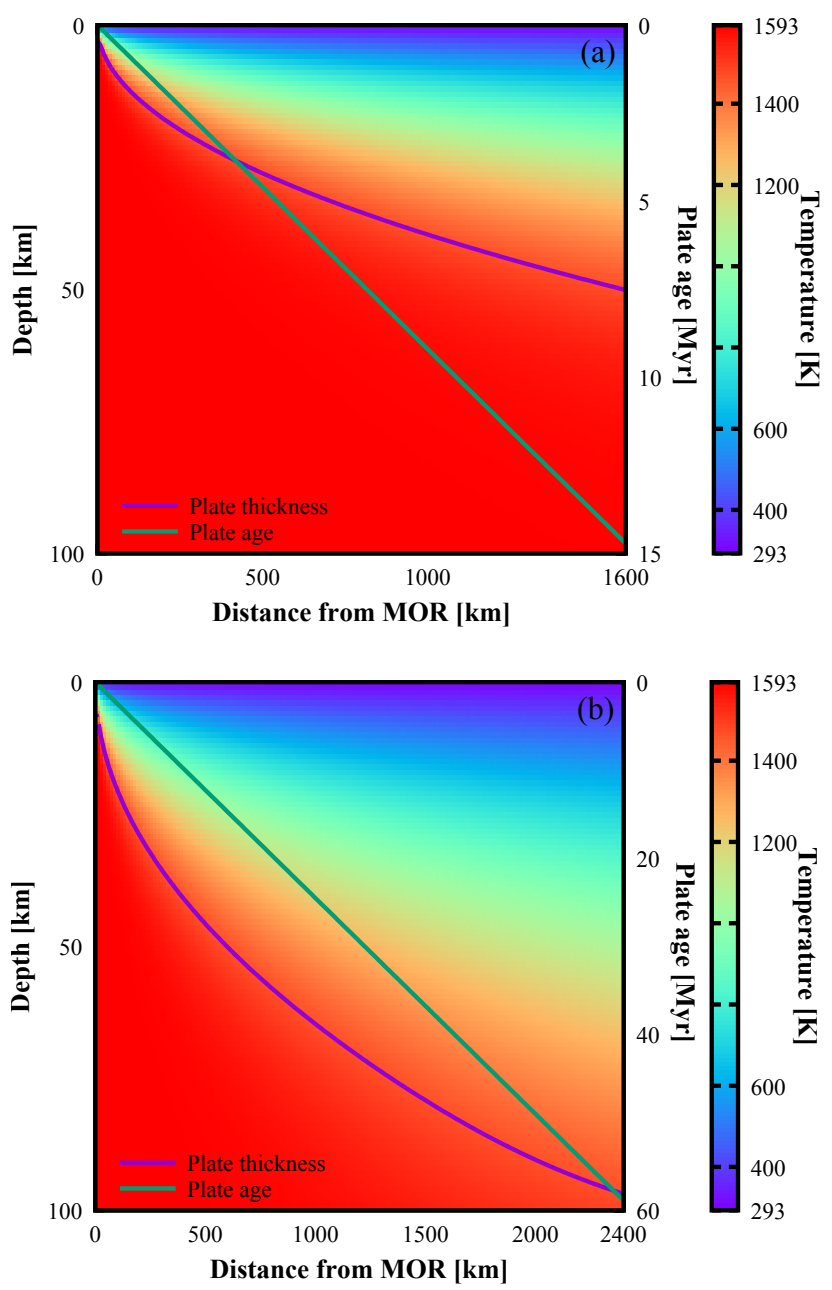

Figure 15. Temperature distribution with depth and distance from the ridge for (a) the OP and (b) the SP.

close to the slab; flow into the trench alters the shape of the plates. After $8.5 \mathrm{Myr}$, plate velocities drop when the slab tip reaches a depth of $660 \mathrm{~km}$ (bottom of the domain) and the steep slab starts to bend in to accommodate lateral sliding over the $660 \mathrm{~km}$ discontinuity. With ongoing subduction, the length of slab being pushed along the $660 \mathrm{~km}$ discontinuity increases and plate velocities increase to pre-sliding levels. At $35 \mathrm{Myr}$, the plate has completely subducted, lying flat at the $660 \mathrm{~km}$ discontinuity, while the trench has retreated a total of $\sim 1000 \mathrm{~km}$.

The AMR based on composition and viscosity follows the outline of the plates as they move through the mantle (Fig. 17), resulting in a local resolution of roughly $3 \mathrm{~km}$ while the mantle is resolved with $\sim 50 \mathrm{~km}$ elements.

\subsubsection{Model 2}

The SP of model 2 steepens for the first $12 \mathrm{Myr}$ (Fig. 18) until full-fledged subduction starts. Subduction is much slower

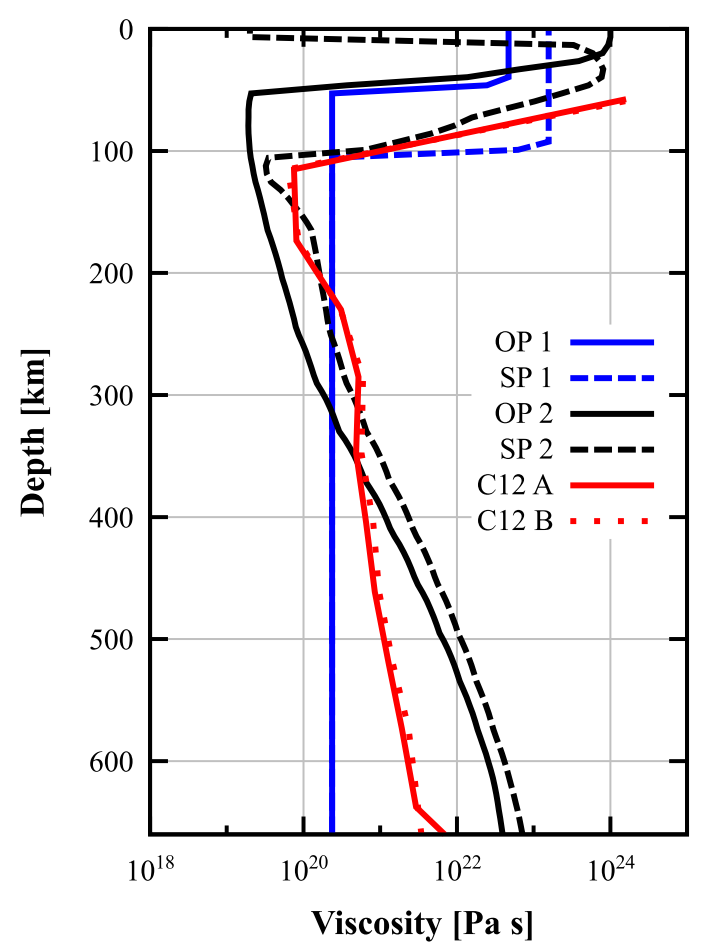

Figure 16. Viscosity profiles at $0 \mathrm{Myr}$ for the OP (at $x=2700 \mathrm{~km}$ ) and SP (at $x=2200 \mathrm{~km}$ ) of models 1 and 2. For comparison, the viscosity profiles derived by Cizkova et al. (2012) are included.

than in model 1: while in model 1 subduction is completed by $35 \mathrm{Myr}$, rollback of the slab in model 2 only sets in around 50 Myr. Simultaneously with slab rollback, the subduction channel is weakened by asthenospheric inflow into the gap between the OP and SP. Formation of this gap is probably initiated by the fact that the OP does not completely release itself from the lateral boundary (see snapshot at $49 \mathrm{Myr}$ ). Even though the slab reaches the bottom boundary around $50 \mathrm{Myr}$ and starts to shallow, it does not lie flat on the $660 \mathrm{~km}$ boundary, but continues to hover above it. Also note the halo of increased strain rate around the tip of the slab and the smallscale strain rate features in the mantle compared to model 1.

\subsection{Discussion}

The evolution of model 1 strongly resembles that of Schellart and Moresi (2013), on whose setup the model is based: the slab first sinks freely until it reaches the $660 \mathrm{~km}$ bottom boundary and then starts draping while rolling back. The absence of folding of the slab at the $660 \mathrm{~km}$ boundary and the differences in timing of the aforementioned events are probably due to the weak, linearly viscous layer of the SP that is left out here (and the lesser extent of the domain in the $y$ direction). This leaves the plate stronger and more resistant to folding than for Schellart and Moresi (2013). Note that our viscoplastic SP of model 2 also does not show draping at the $660 \mathrm{~km}$ boundary. 

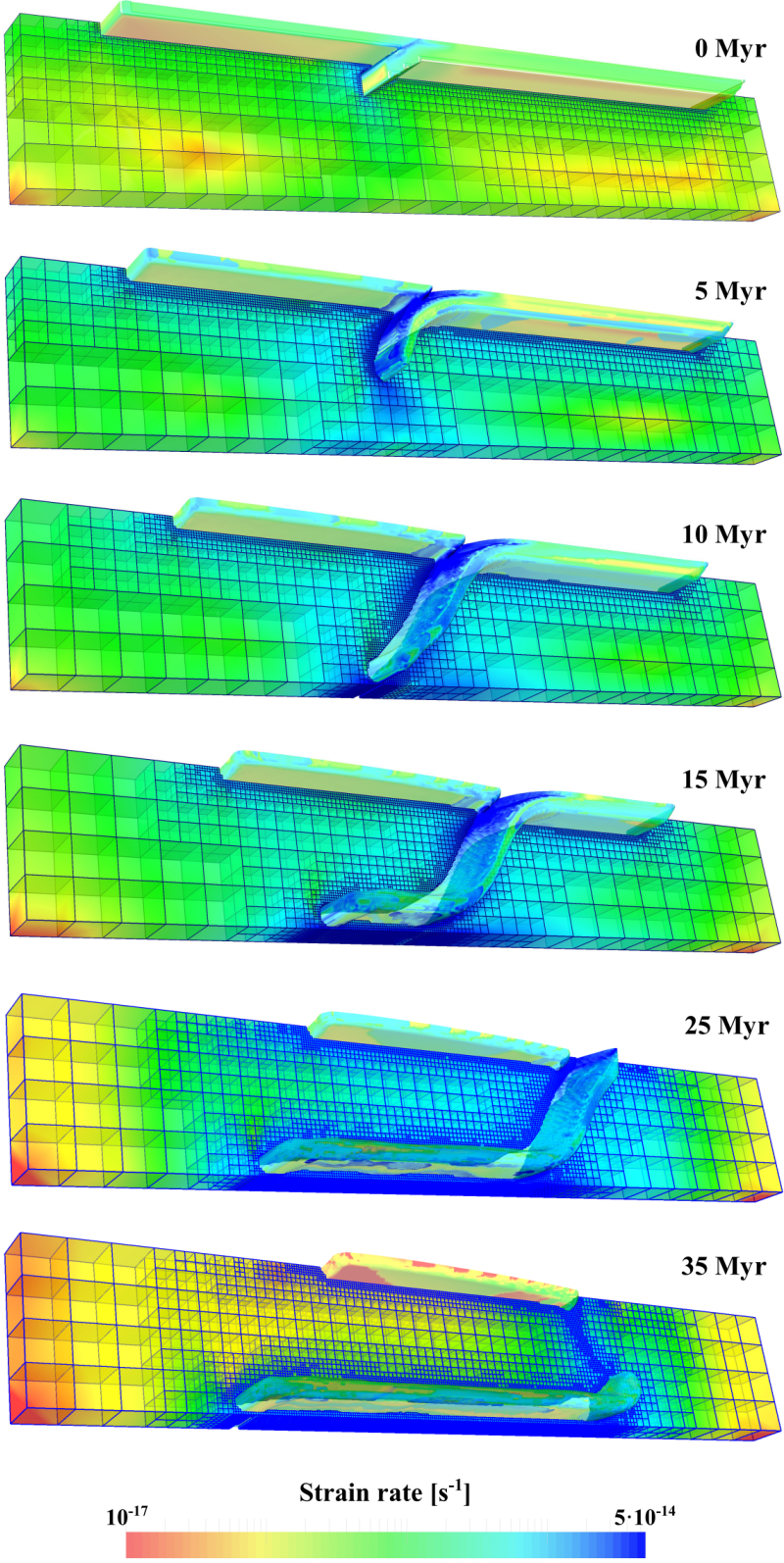

Figure 17. Model 1 - strain rate Frobenius norm $\sqrt{\dot{\epsilon}: \dot{\epsilon}}$ over time together with SP and OP isocontours. Also shown is the adaptive mesh following the SP into the mantle.

In switching from model 1 to this thermomechanically coupled model 2, we found changes to the setup were necessary to avoid subduction of the plate at locations other than the slab tip (i.e., the sides and back of the plate would subduct as well) due to high mantle temperatures. Therefore, we added the adjacent plate and transform fault. By locating the plate ridges at the left and right vertical boundaries, free motion of the plates perpendicular to the trench is still enabled. Mesh resolution here was reduced over time because the refinement strategy chosen focused on the compositional
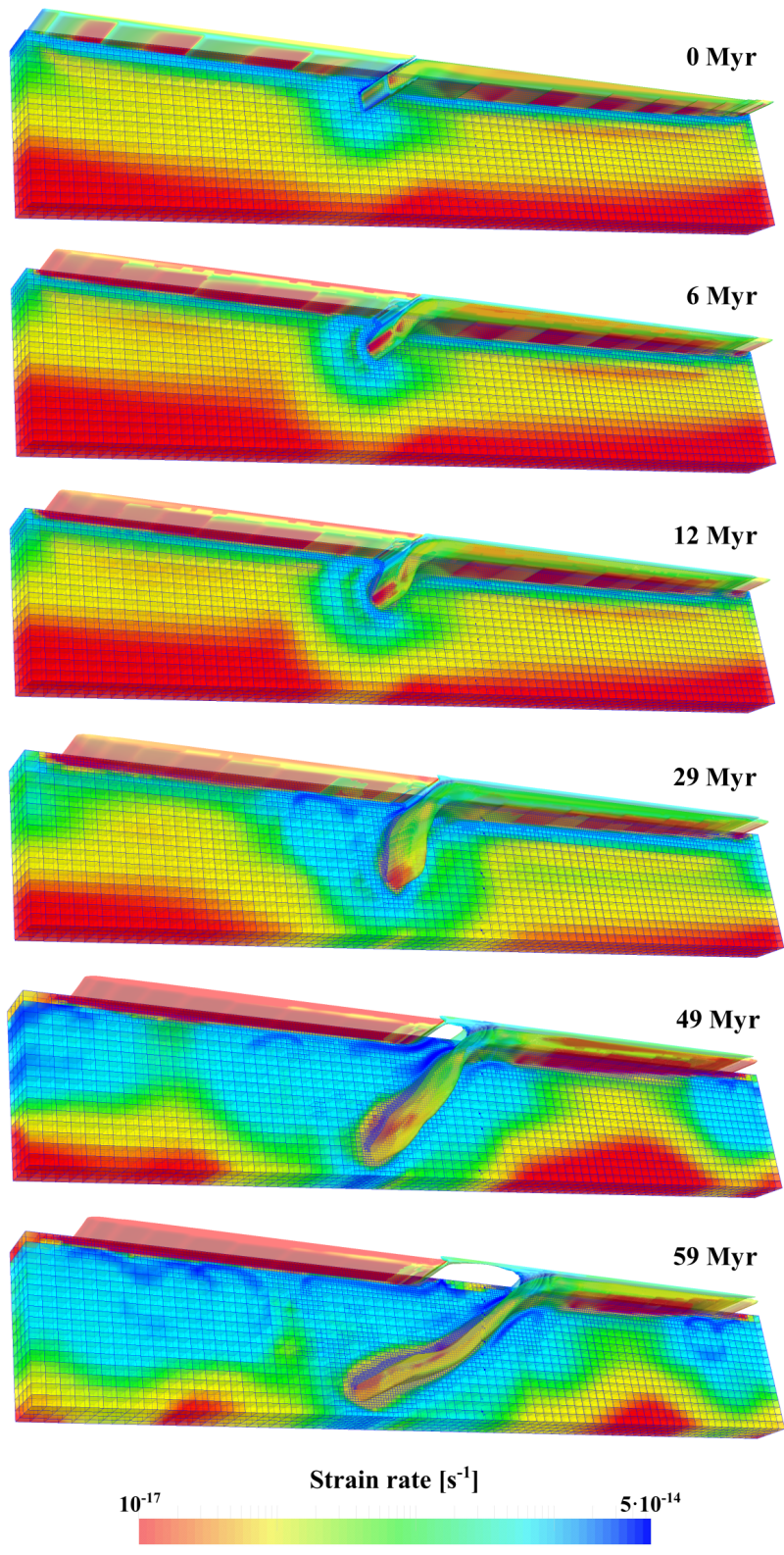

Figure 18. Model 2 - strain rate Frobenius norm $\sqrt{\dot{\epsilon}: \dot{\epsilon}}$ over time together with SP, SP crust and OP isocontours. Also shown is the adaptive mesh following the SP into the mantle.

fields, which moved away from the boundaries. This unfortunately increased the coupling of the OP plate to the left boundary, limiting the plate's ability to move.

The subduction evolution of model 1 and 2 in Figs. 17 and 18 clearly differs. Models in the Appendix of Schellart and Moresi (2013) have shown that the addition of adjacent plates in itself does not affect the geometry of the SP over time (although velocities are affected). A test with a uniform viscosity adjacent plate for our model 1 corroborates this. Therefore, the differences derive from the temperature, pressure, strain rate and composition-dependent rheology. In- 


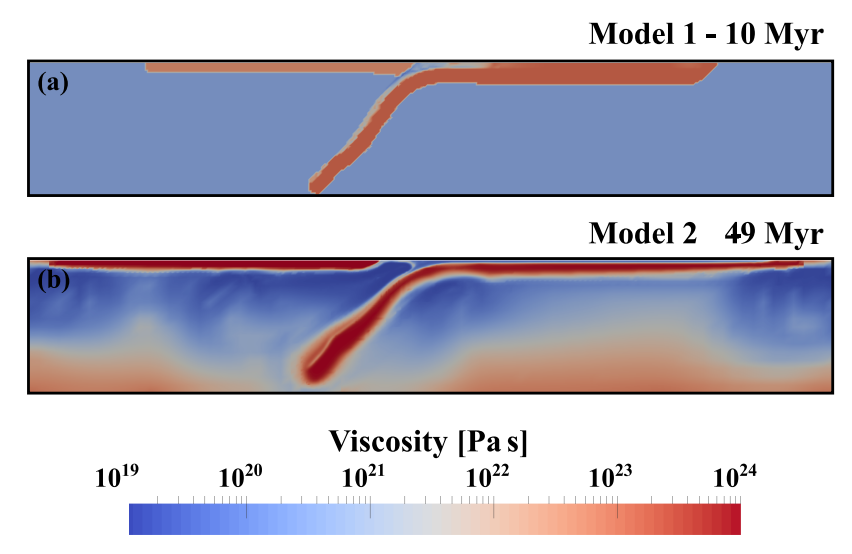

Figure 19. Viscosity snapshots of (a) model 1 and (b) model 2 at comparable moments in the respective subduction evolutions.

deed, a snapshot (Fig. 19) of the viscosity field of the SPs and OPs shows that the viscosity of the plates of model 2 is about an order of magnitude higher (cutoff at $10^{24} \mathrm{Pas}$ ). As both the SP and the OP of model 2 keep growing at the trench, they also experience more mantle drag than in model 1. Moreover, the model 2 slab tip is surrounded by a higher-viscosity area due to local cooling of the mantle. These rheological differences slowing down the subduction process are also evident from the strain rate in Figs. 17 and 18, showing a much weaker slab and mantle in model 1 . A full investigation into the differences between mechanical and thermomechanical viscoplastic models is beyond the scope of this paper.

More elaborate models of subduction should incorporate phase changes and latent heat effects as well as adiabatic and shear heating. This is also possible with ASPECT and we include an example of such a 2-D model in Appendix B.

\section{Discussion}

The four benchmarks shown using our viscoplasticity implementations in ASPECT either reproduce the available analytical solution (Sect. 3.1) or compare well with theory (Sect. 3.2) or the results of other codes (Sect. 3.2-3.4). Thus verifying our implementations, the four benchmarks allowed us to set up a 4-D model of oceanic subduction, exemplifying the functionality that our implementations have added.

It should be noted that although the rheology described in this paper is often applied in numerical modeling, more elaborate laws have been proposed. For example, Gerya and Yuen (2007) included dilatant materials and Choi and Petersen (2015) argue that numerical models should incorporate an initially associated plastic flow rule that evolves into a non-associated flow rule with increased slip to assure persistent Coulomb shear band angles while avoiding unlimited dilatation. The inclusion of an intrinsic length scale in the plasticity formulation would work to remove the mesh dependence of the rheology (e.g., strain gradient plasticity; Fleck and Hutchinson, 2001). Another addition would be to include plastic softening or hardening - changes in the yield surface due to the accumulated strain. Considering creep flow laws, improvements could be made by adding Peierls creep, a dislocation mechanism acting at low temperatures and/or high stresses (e.g., in parts of the slab; Karato, 2008; Duretz et al., 2011; Garel et al., 2014). Other authors such as Farrington et al. (2014) and Fourel et al. (2014) have investigated the effect of incorporating elasticity into models of lithosphere subduction, demonstrating that although observables such as dip angle, slab morphology and plate motion are not affected, an elastoviscous or elastoviscoplastic rheology leads to different viscosities in the hinge of the slab.

Incorporating more realistic nonlinear rheologies such as described in this paper creates the necessity for additional nonlinear iterations within a single time step. Also, we have seen that at higher mesh resolutions, more of such iterations are required to converge the solution. This greatly increases model run time and therefore it is important to implement a more efficient nonlinear solving strategy than the Picard iterations currently used by ASPECT. The more sophisticated Newton solver (see for example Popov and Sobolev, 2008; May et al., 2015; Rudi et al., 2015; Kaus et al., 2016; Wilson et al., 2017) will help achieve faster convergence. Convergence behavior has also been suggested to improve from including elasticity (Kaus, 2010), but especially dynamic pressure-dependent plasticity remains difficult to converge for both Picard iterations and Newton solvers (Spiegelman et al., 2016).

Nonlinear rheologies also affect the linear solver by introducing large viscosity gradients. Different strategies to reduce the increased computational time and under- and overshooting of the numerical approximation of the resulting pressure gradient are available in ASPECT. For one, one can reduce the linear tolerance (while making sure the results do not change significantly), as was shown in Sect. 3.1. Secondly, a cheap Stokes solver can be employed, although this does not help for each model setup (compare Sect. 3.1 and 3.4). Thirdly, averaging the contributions of the compositional field to the viscosity and other material properties in a specific point reduces the sharpness of viscosity boundaries, making the problem easier to solve, but with the choice of averaging method affecting the model evolution (Sect. 3.4 and Appendix A). Lastly, averaging of material properties such as viscosity and density over each element reduces pressure oscillations (Heister et al., 2017), but can also influence the model evolution as was shown in Sect. 3.4.

\section{Conclusion and outlook}

Numerical modeling of intricate geodynamic processes such as crust and lithosphere deformation and plate subduction encompasses challenges at different levels. For one, the 4$\mathrm{D}$ nature of the subduction process requires state-of-the-art 
numerical methods to efficiently handle the parallel computations necessary for such large problem sets. Secondly, models should incorporate realistic (non)linear rheologies to mimic nature as close as possible. Thus, the need arises for algorithms that can solve highly nonlinear equations and deal with large viscosity contrasts effectively. Thirdly, far-field effects of mantle flow and plate motion cannot be ignored, and neither can topography building, resulting in a demand for complex boundary conditions such as open boundaries (Chertova et al., 2012) and free surfaces (Kaus et al., 2010; Crameri et al., 2012; Rose et al., 2017).

In this paper, we have shown that the open-source code ASPECT is up to these challenges. Building on its modern, massively parallel numerical methods, here we have outlined our basic additions that enable viscoplastic crust and lithosphere modeling. We then tested and verified the algorithms with four different benchmarks that are well-known in the geodynamic modeling community. Last, we highlighted the possibilities arising from the adaptations with 4-D thermomechanically coupled viscoplastic models of interoceanic subduction, showing that ASPECT is a serious contender in the field of lithospheric subduction modeling.
The continued development of ASPECT based on the needs of its expanding user and developer community ensures ever-growing capacities and possibilities. Important recent additions are a full free surface (Rose et al., 2017), the formation and migration of partial melt (Dannberg and Heister, 2016), active particles (Gassmöller et al., 2016), a discontinuous Galerkin method for advection (He et al., 2017), and a Newton solver (Fraters et al., 2017). Also, the extensive user manual (Bangerth et al., 2017a) accompanying all developments is a great asset for new and current users. In consequence, opportunities for future research are reinforced and a firm foundation is provided for ASPECT in the geodynamics community.

Code availability. Our simulations were performed with ASPECT version 1.5.0 (Bangerth et al., 2017b), available on GitHub. The rheology implementations described in this paper can be found on Zenodo (Glerum, 2017) and GitHub https://github.com/anne-glerum/ paper-aspect-plasticity-subduction-data together with all the plugins and input files needed to reproduce the benchmarks and 3-D subduction models. This directory includes postprocessing scripts to produce the plots in this paper as well. 
Appendix A: Self-consistent subduction and compositional averaging

As discussed in Sect. 2.2.2, the choice of averaging method for models of multiple compositions can significantly influence the results (Deubelbeiss and Kaus, 2008; Schmeling et al., 2008). Based on a number of experiments, we have chosen the infinity norm as method of choice for this paper. One of the models on which this choice is based is that of Schmeling et al. (2008), on which we will elaborate below.

\section{A1 Model setup}

The 2-D linear viscous model is composed of three compositions: the mantle, subducting lithosphere and sticky air to allow for surface topography build-up and detachment of the lithosphere from the top boundary (Fig. A1, Table A1). The subducted part of the lithosphere supplies the force to start subduction; the slab tip either extends into the mantle at a $90^{\circ}$ angle (case 1) or at a $34^{\circ}$ angle (case 2). The four different averaging methods in Eqs. (15)-(18) are tested at different resolutions.

\section{A2 Model results}

The evolution of subduction for case 1 is summarized in a plot of the slab tip depth over time in Fig. A2a. It is clear that the effect of the averaging method dominates over that of resolution, but that both are significant. As do Schmeling et al. (2008) (shaded areas in Fig. A2), we find that subduction is fastest for harmonic averaging and slowest for arithmetic averaging. For a given method, a higher resolution speeds up subduction, except for harmonic averaging. For an explanation of these results, see Schmeling et al. (2008). Comparison with the absolute results of Schmeling et al. (2008) is complicated by different computational methods, elements, minimum resolutions and mesh configurations, e.g., compare the solid and dashed dark red lines in Fig. A2. A much better agreement in slab tip evolution between the different averaging methods is found for case 2 (Fig. A2b), in which the initial slab dip is more realistic. The trends in resolution and averaging dependence remain the same.

Snapshots of the viscosity field for case 1 are shown in Fig. A3: the infinity norm model's field shows the least artifacts from compositional under- and overshoot; the harmonically averaged model shows the most. Wall time for the first 2000 time steps is reported for the highest-resolution model of each averaging method in Table A2; the infinity norm is the most computationally expensive.

\section{A3 Choice of averaging method}

The infinity norm selects the parameters of the field that is greatest at a specific point. It thus counteracts the numerical diffusion of the compositional boundaries in the calculation of composition-dependent parameters, but unfortunately also
Table A1. The self-consistent subduction benchmark model parameters.

\begin{tabular}{ll}
\hline Parameter & Value (unit) \\
\hline Domain width & $3000 \mathrm{~km}$ \\
Domain height & $750 \mathrm{~km}$ \\
Maximum resolution & $256 \times 64-2,048 \times 512 \mathrm{el}$. \\
Minimum resolution & $128 \times 32 \mathrm{el}$. \\
Gravity acceleration & $9.81 \mathrm{~m} \mathrm{~s}^{-2}$ \\
Stokes solver tolerance & $10^{-7}$ \\
Model end time & $100 \mathrm{Myr}$ \\
Temperature polynomial degree & 1 \\
No. of cores & $8-18$ \\
Wall time & $27-71 \mathrm{~h}^{-18}$ \\
\hline Sticky air & \\
\hline Constant density $\rho$ & $1 \mathrm{~kg} \mathrm{~m}^{-3}$ \\
Constant viscosity $\mu$ & $10^{19} \mathrm{~Pa} \mathrm{~s}^{-3}$ \\
\hline Subducting lithosphere & \\
\hline Constant density $\rho$ & $3300 \mathrm{~kg} \mathrm{~m}^{-3}$ \\
Constant viscosity $\mu$ & $10^{23} \mathrm{~Pa} \mathrm{~s}$ \\
\hline Mantle & \\
\hline Constant density $\rho$ & $3200 \mathrm{~kg} \mathrm{~m}^{-3}$ \\
Constant viscosity $\mu$ & $0^{21} \mathrm{~Pa} \mathrm{~s}^{-3}$ \\
\hline
\end{tabular}

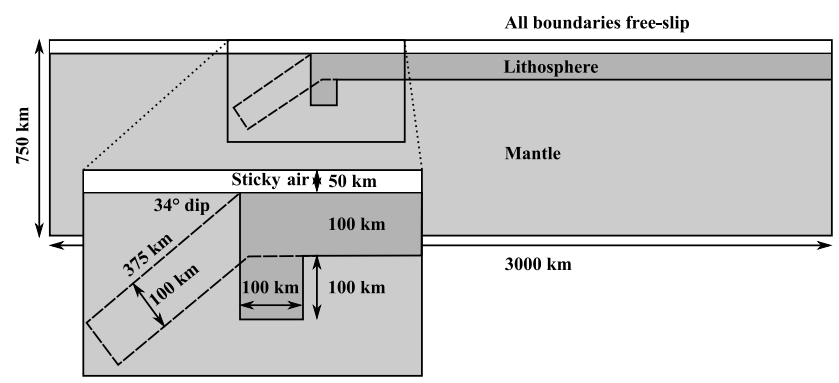

Figure A1. The self-consistent subduction benchmark model setup. The mantle, subducting plate and sticky air are represented by three compositional fields of constant viscosity. The slab geometry of case 1 is indicated in solid lines; the dashed line outlines the slab tip of case 2 (based on case 3 of Schmeling et al., 2008).

sharpens possible viscosity contrasts between the fields. This increases computational time. For more complex models in which wall time is an important factor, we recommend using the geometric averaging method. 

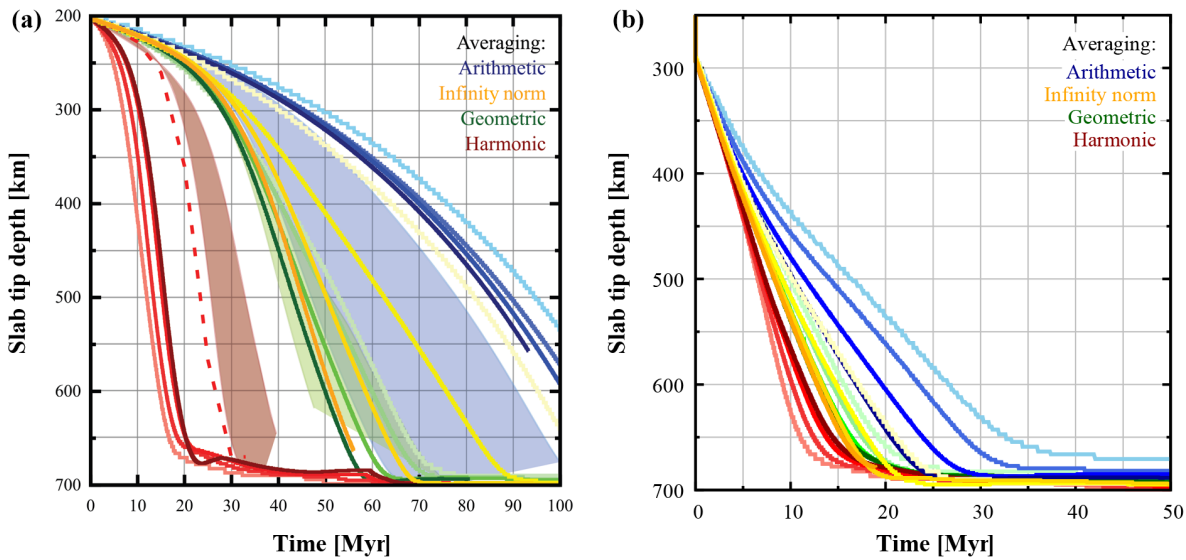

Figure A2. Slab tip depth versus model time for four different averaging methods of the contribution of the compositional fields to viscosity. Colors indicate the averaging method, while one color goes from light to dark with local resolution, which varies from $256 \times 64$ elements to $2048 \times 512$ elements. Minimum resolution is always $128 \times 32$ elements. (a) Case 1 . The dashed red line model has a resolution varying from $128 \times 128$ to $2048 \times 2048$ elements. Shaded areas represent results of Schmeling et al. (2008, Fig. 6). (b) Case 2.
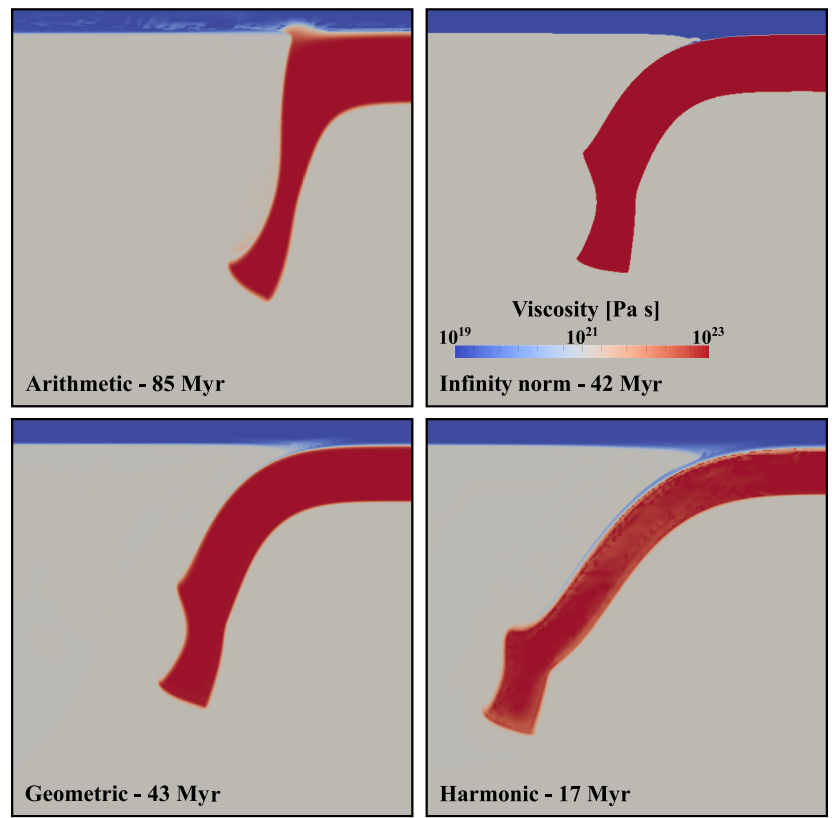

Figure A3. Viscosity field for each averaging method at $2048 \times 512$ element local resolution at similar moments in the subduction evolution.

Table A2. Wall time for time step 2000 of the self-consistent subduction benchmark for different viscosity averaging methods using 28 cores.

\begin{tabular}{lr}
\hline Averaging method & Wall time $t_{2000}[\mathrm{~s}]$ \\
\hline Arithmetic & $9.76 \times 10^{4}$ \\
Infinite norm & $3.84 \times 10^{5}$ \\
Geometric & $7.52 \times 10^{4}$ \\
Harmonic & $5.88 \times 10^{4}$ \\
\hline
\end{tabular}


Appendix B: Compressible subduction with phase changes, open boundaries and a free surface

With this example of 2-D subduction, we highlight some of the more recent additions to ASPECT: compositional field reactions (which can be used to implement phase changes), the true free surface (Rose et al., 2017) and traction boundary conditions. These features are used to set up a model of thermomechanically coupled viscoplastic subduction in which the plate motions are either prescribed on the vertical boundaries, or, at a later stage, material is free to move in or out of the model domain. A compressible formulation of the governing equations is used, including shear heating, adiabatic heating and latent heat:

$-\nabla \cdot(2 \eta \dot{\epsilon})+\nabla P=\rho \boldsymbol{g}$,

$\nabla \cdot \boldsymbol{v}=-\beta \rho \boldsymbol{v} \cdot \boldsymbol{g}$,

$\left(\rho c_{p}-\rho T \Delta S \frac{\partial X}{\partial T}\right)\left(\frac{\partial T}{\partial t}+\boldsymbol{v} \cdot \nabla T\right)$

$-\nabla \cdot k \nabla T=(2 \eta \dot{\epsilon}): \dot{\epsilon}$

$+\alpha T \boldsymbol{v} \cdot \nabla P$

$+\rho T \Delta S \frac{\partial X}{\partial P} \boldsymbol{v} \cdot \nabla P$,

where $\beta$ is the compressibility $\frac{1}{\rho} \frac{\partial \rho}{\partial P}, \rho=\rho_{0}(1.0+\beta(P-$ $\left.\left.P_{0}\right)\right)\left(1.0-\alpha\left(T-T_{0}\right)\right), \Delta S=\gamma_{\mathrm{t}} \frac{\delta_{\mathrm{t}}}{\rho^{2}}$ and $\frac{\partial X}{\partial T}=-\gamma_{\mathrm{t}} \frac{\partial X}{\partial P}$.

Phase changes (changes of one compositional field into another with different material properties) are implemented by extending our, now compressible, multicomponent viscoplastic material model with a depth-dependent transition function (e.g., Christensen and Yuen, 1985):

$X=\frac{1}{2}\left[1.0+\tanh \left(\frac{z-z_{\mathrm{t}}-\gamma_{\mathrm{t}} \frac{z_{\mathrm{t}}}{P_{\mathrm{t}}}\left(T-T_{\mathrm{t}}\right)}{d \frac{z_{\mathrm{t}}}{P_{\mathrm{t}}}}\right)\right]$.

$X$ represents the fraction of the new phase, $P_{\mathrm{t}}, T_{\mathrm{t}}$ and $z_{\mathrm{t}}$ are the reference pressure, temperature and depth of the transition, respectively, and $d$ the transition half-width in terms of pressure (assuming $P=P_{\text {lith }}=\rho g z$ ). The phase function derivatives in Eq. (B3) are computed as in the latent heat plug-in of the Material model module.

Open boundary conditions are newly implemented as a plug-in to the Traction boundary conditions module by prescribing the traction as (Chertova et al., 2012)

$\tau=-P_{\text {lith }} \hat{\boldsymbol{n}}$,

with $\hat{n}$ the outward normal to the domain boundary. $P_{\text {lith }}$ is the lithostatic pressure calculated by numerical integration along the domain boundary of the density (i.e., the temperature and composition) of the previous time step.

\section{B1 Model setup}

The compressible subduction model considers oceancontinent subduction in a domain of $1600 \mathrm{~km}$ by $1000 \mathrm{~km}$

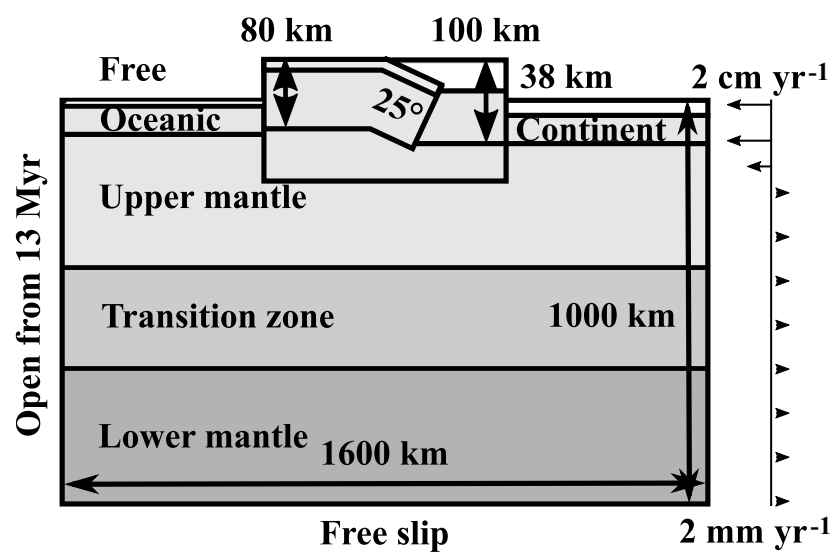

Figure B1. Compressible subduction model setup: subduction of an oceanic plate of $80 \mathrm{~km}$ thickness underneath a $100 \mathrm{~km}$ thick continental plate is initiated with an $80 \mathrm{~km}$ slab. Different compositional fields are used to describe the oceanic and continental crusts and the upper mantle (UM), transition zone (TZ), and lower mantle (LM) material. A 2-times viscosity increase is also included at the $660 \mathrm{~km}$ phase boundary. The top boundary is a true free surface; the right vertical boundary has a prescribed in- and outflow as indicated from $8 \mathrm{Myr}$ onward. A similar flow ( $4 \mathrm{~cm} \mathrm{yr}^{-1}$ inflow) is prescribed on the left boundary until $13 \mathrm{Myr}$, when the boundary is opened.

(Fig. B1). The model includes phase changes around 410 and $660 \mathrm{~km}$ depth; see Table B1. An inward plate velocity is prescribed on the upper part of the left vertical boundary for the first $13 \mathrm{Myr}$ at $4 \mathrm{~cm} \mathrm{yr}^{-1}$, while prescribed outward mantle velocities compensate for this volume increase. After $13 \mathrm{Myr}$, material is free to move in or out of the domain through open boundary conditions on the left boundary. On the right boundary, no-slip conditions are switched to a prescribed velocity profile after $8 \mathrm{Myr}$, with a plate inflow of $2 \mathrm{~cm} \mathrm{yr}^{-1}$. Apart from the subducting plate crust, which is of linear viscosity, all materials are nonlinear viscoplastic. At $200 \mathrm{~km}$, crustal material is transformed to mantle material (as is done, for example, by Androvicova et al., 2013). Initial temperature is based on an adiabatic profile in the mantle and linear profiles in the plates.

\section{B2 Model results}

Figure B2 shows the evolution of the compressible subduction model in terms of viscosity. When the left boundary is opened at $13 \mathrm{Myr}$, just after the slab has reached the $410 \mathrm{~km}$ phase boundary, sinking velocities increase to $10.5 \mathrm{~cm} \mathrm{yr}^{-1}$. Upon reaching the $660 \mathrm{~km}$ phase boundary (with a 2-fold viscosity increase), the slab slows down to about $5 \mathrm{~cm} \mathrm{yr}^{-1}$. The tip of the slab is impeded by the $660 \mathrm{~km}$ boundary and moves at around $1 \mathrm{~cm} \mathrm{yr}^{-1}$ along the boundary.

The change in flow through the left boundary is depicted in Fig. B3: when the left domain boundary is opened up by prescribing stresses instead of a fixed velocity profile, first of all a downward shift of the transition from in- to outflow 
Table B1. Compressible subduction model parameters.

\begin{tabular}{|c|c|}
\hline Parameter & Value (unit) \\
\hline Domain length & $1600 \mathrm{~km}$ \\
\hline Domain height & $1000 \mathrm{~km}$ \\
\hline Element size & $\begin{array}{l}1.6 \times 1.6- \\
25 \times 25 \mathrm{~km}\end{array}$ \\
\hline Gravitational acceleration & $9.81 \mathrm{~m} \mathrm{~s}^{-2}$ \\
\hline Surface temperature & $273 \mathrm{~K}$ \\
\hline Mantle potential surface temperature & $1600 \mathrm{~K}$ \\
\hline Thermal conductivity $k$ & $4.0 \mathrm{~W} \mathrm{~m}^{-1} \mathrm{~K}^{-1}$ \\
\hline Specific heat $c_{\mathrm{p}}$ & $1000 \mathrm{~J} \mathrm{~kg}^{-1} \mathrm{~K}^{-1}$ \\
\hline Thermal expansivity $\alpha$ & $3.0 \times 10^{-5} \mathrm{~K}^{-1}$ \\
\hline Reference viscosity $\mu_{\text {ref }}$ & $10^{21} \mathrm{Pas}$ \\
\hline Viscosity averaging & Eq. (16) \\
\hline Effective viscosity $\mu_{\mathrm{eff}}^{\mathrm{vp}}$ & Eq. (12) \\
\hline Minimum viscosity $\mu_{\min }$ & $10^{20} \mathrm{Pas}$ \\
\hline Maximum viscosity $\mu_{\max }$ & $10^{24} \mathrm{Pas}$ \\
\hline Viscosity capping $\mu_{\text {eff }}$ & Eq. (13) \\
\hline Compressibility $\beta$ & $5.124 \times 10^{-12} \mathrm{~Pa}^{-1}$ \\
\hline $410 \mathrm{~km}$ Clapeyron slope $\gamma_{410}$ & $2.0 \times 10^{6} \mathrm{~Pa} \mathrm{~K}^{-1}$ \\
\hline $660 \mathrm{~km}$ Clapeyron slope $\gamma_{660}$ & $-1.5 \times 10^{6} \mathrm{PaK}^{-1}$ \\
\hline Transition widths $d$ & $10 \mathrm{~km}$ \\
\hline $410 \mathrm{~km}$ density contrast $\delta_{\rho_{410}}$ & $273 \mathrm{~kg} \mathrm{~m}^{-3}$ \\
\hline $660 \mathrm{~km}$ density contrast $\delta_{\rho_{660}}$ & $342 \mathrm{~kg} \mathrm{~m}^{-3}$ \\
\hline $410 \mathrm{~km}$ transition pressure $P_{410}$ & $1.325 \times 10^{10} \mathrm{~Pa}$ \\
\hline $660 \mathrm{~km}$ transition pressure $P_{660}$ & $2.16 \times 10^{10} \mathrm{~Pa}$ \\
\hline Max. no. of nonlinear iterations NIs & 50 \\
\hline Surface pressure normalization & no \\
\hline No. of cores & 90 \\
\hline DOFs/core & $\sim 13000$ \\
\hline Wall time & $\sim 69 \mathrm{~h}$ \\
\hline
\end{tabular}

is seen. Moreover, the subducting plate velocity initially increases up to $11 \mathrm{~cm} \mathrm{yr}^{-1}$, together with an increase in transition and lower-mantle velocity. When the slab reaches the $660 \mathrm{~km}$ phase boundary around $16 \mathrm{Myr}$, lower-mantle outflow goes up rather uniformly, but in- and outflow above decreases. When the slab tip moves over the $660 \mathrm{~km}$ boundary, all flow decreases in magnitude - gradually in the mantle and uniformly in the lower mantle.

The phase changes are clearly expressed in the density fields: the density isocontours in Fig. B2 show positive topography in the slab at the $410 \mathrm{~km}$ discontinuity, while the $660 \mathrm{~km}$ transition in the slab occurs deeper. The deformation of the surface at $18 \mathrm{Myr}$ shows a lowered subducting plate (about $1 \mathrm{~km}$ below the initial top boundary), a topographic rise of continental crust above the subducting slab (of maximally $8 \mathrm{~km}$ ) and an elevated overriding continental plate (about $4 \mathrm{~km}$ ).

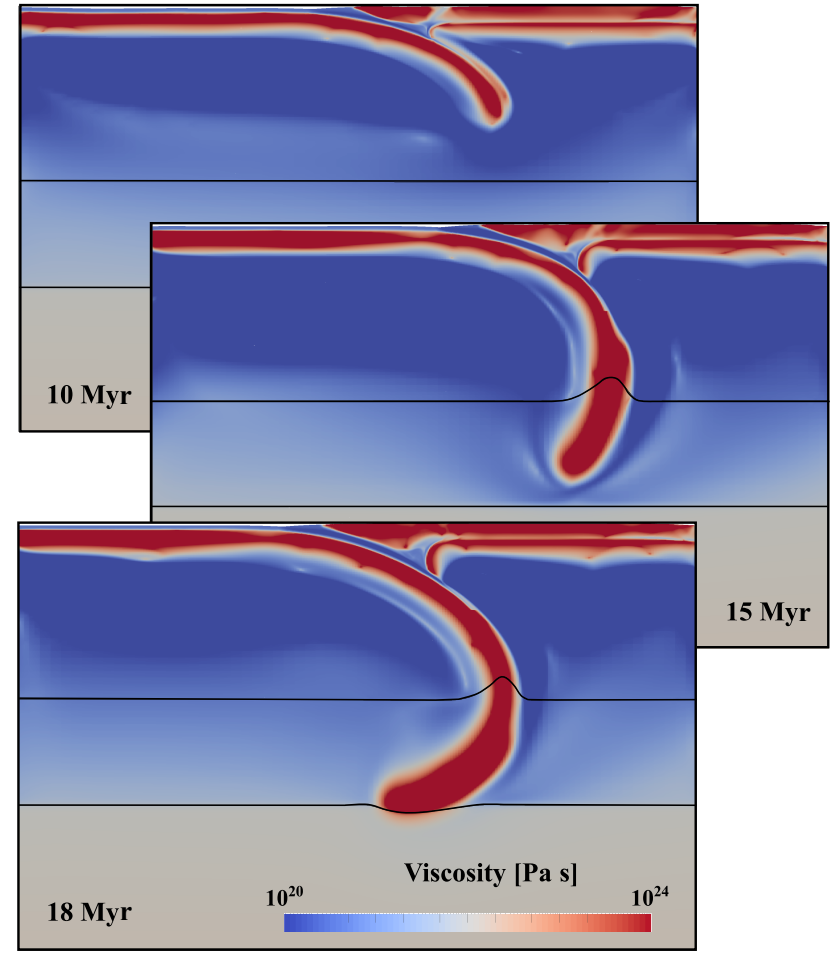

Figure B2. Compressible subduction evolution in terms of viscosity. Density is contoured at 3700 and $4200 \mathrm{~kg} \mathrm{~m}^{-3}$, demonstrating phase boundary topography in the slab.

\section{B3 Discussion and conclusion}

Figure B3 illustrates the forcing boundary conditions exert on subduction models: upon opening the left boundary a different flow pattern develops that changes over time in reaction to the internal dynamics of the system, i.e., it is more representative than the prescribed velocity profile. Together with the phase boundaries and free surface, such open boundary conditions allow for more realistic models of subduction. 
Table B2. Compressible subduction material parameters.

\begin{tabular}{lllllll}
\hline Parameter & LM & TZ & UM & Crust SP & Crust OP & Unit \\
\hline Activation volume $V_{\mathrm{df}}$ & $1.0 \times 10^{-6}$ & $4.0 \times 10^{-6}$ & $4.0 \times 10^{-6}$ & $4.0 \times 10^{-6}$ & $4.0 \times 10^{-6}$ & $\mathrm{~m}^{3} \mathrm{~mol}^{-1}$ \\
Activation energy $Q_{\mathrm{df}}$ & $1.0 \times 10^{5}$ & $3.35 \times 10^{5}$ & $3.35 \times 10^{5}$ & $3.35 \times 10^{5}$ & $3.35 \times 10^{5}$ & $\mathrm{Jmol}^{-1}$ \\
Prefactor $B_{\mathrm{df}}$ & $1.0 \times 10^{-19}$ & $5.92 \times 10^{-11}$ & $5.92 \times 10^{-11}$ & $1.92 \times 10^{-11}$ & $1.92 \times 10^{-11}$ & $\mathrm{~Pa}^{-\mathrm{n}} \mathrm{s}^{-1}$ \\
Scaling factor $\beta_{\mathrm{df}}$ & 1.0 & 1.0 & 1.0 & 1.0 & 1.0 & - \\
Activation volume $V_{\mathrm{dl}}$ & $14 \times 10^{-6}$ & $14 \times 10^{-6}$ & $14 \times 10^{-6}$ & 0.0 & 0.0 & $\mathrm{~m}^{3} \mathrm{~mol}^{-1}$ \\
Activation energy $Q_{\mathrm{dl}}$ & $4.0 \times 10^{5}$ & $4.0 \times 10^{5}$ & $4.0 \times 10^{5}$ & 0.0 & $2.23 \times 10^{5}$ & $\mathrm{Jmol}^{-1}$ \\
Prefactor $B_{\mathrm{dl}}$ & $5.5 \times 10^{-20}$ & $5.5 \times 10^{-16}$ & $5.5 \times 10^{-16}$ & $1.0 \times 10^{-21}$ & $1.1 \times 10^{-28}$ & $\mathrm{~Pa}^{-\mathrm{n}} \mathrm{s}^{-1}$ \\
Stress exponent $n$ & 3.0 & 3.0 & 3.0 & 1.0 & 4.0 & - \\
Scaling factor $\beta_{\mathrm{dl}}$ & 2.0 & 2.0 & 2.0 & 1.0 & 1.0 & - \\
Internal angle of friction $\phi$ & 30 & 30 & 30 & 0.0 & 0.0 & $\circ$ \\
Cohesion $C$ & $2.0 \times 10^{7}$ & $2.0 \times 10^{7}$ & $2.0 \times 10^{7}$ & $2.0 \times 10^{7}$ & $1.0 \times 10^{8}$ & $\mathrm{~Pa}$ \\
Initial viscosity $\mu_{\text {init }}$ & $1.0 \times 10^{22}$ & $1.0 \times 10^{21}$ & $1.0 \times 10^{20}$ & $5.0 \times 10^{22}$ & $5.0 \times 10^{22}$ & $\mathrm{Pas}$ \\
Reference temperature $T_{0}$ & 1800 & 1800 & 1800 & 400 & 400 & $\mathrm{~K}$ \\
Reference density $\rho_{0}$ & 3915 & 3575 & 3300 & 3150 & 2900 & $\mathrm{kgm}$ \\
\hline
\end{tabular}

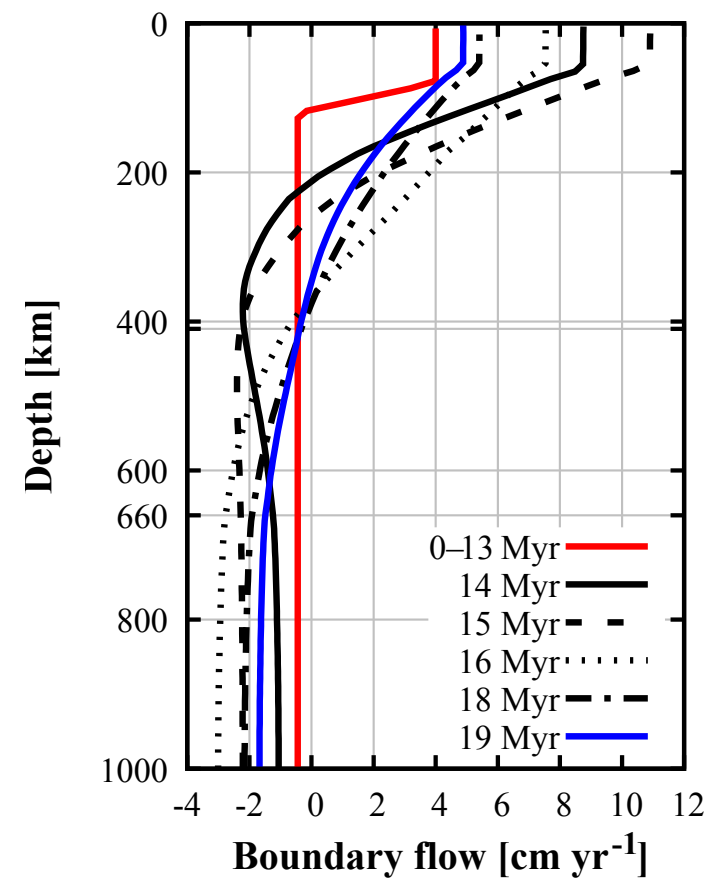

Figure B3. Left boundary in- and outflow for the compressible subduction model. In red the velocity profile that is prescribed for the first $13 \mathrm{Myr}$. In black are the velocity profiles obtained with open boundary conditions. Positive values represent inflow and negative outflow. 
Author contributions. AG developed the code implementations and performed the simulations for this paper, with the exception of the 2-D compressible subduction model in the Appendix. This latter model was constructed by $\mathrm{CB}$ under the supervision of $\mathrm{CT}, \mathrm{AG}$ and MF, based on the code of MF (model setup) and AG (open boundary conditions, rheology). CT provided the model output of several benchmarks of his code ELEFANT for comparison and discussion. AG prepared the paper with contributions from CT and WS.

Competing interests. The authors declare that they have no conflict of interest.

Disclaimer. The authors declare that they have nothing to disclaim.

Acknowledgements. We are grateful to the reviewers Dave May and Boris Kaus for their detailed and constructive reviews. We thank Wolfgang Bangerth, Timo Heister, Rene Gassmöller and Juliane Dannberg for their precious help concerning the use and fine-tuning of ASPECT. We also thank Harro Schmeling for providing the data of his 2008 subduction benchmark paper and Stefan Markus Schmalholz for the slab detachment data of his 2011 paper. Arie P. van den Berg and John Naliboff are thanked for constructive discussions. This work was funded by The Netherlands Research Centre for Integrated Solid Earth Science (grant no. ISES-2012-89) and the Research Council of Norway through its Centres of Excellence funding scheme (project no. 223272). ISES also provided financial support for the in-house computer on which computations were done. ASPECT is hosted by the Computational Infrastructure for Geodynamics (CIG), which is supported by the National Science Foundation award NSF-094946. We also thank CIG for support for Anne Glerum, Cedric Thieulot and Menno Fraters to attend the ASPECT Hackathons. We acknowledge the work of Ian Rose (averaging of compositional fields), Robert Myhill (dislocation and diffusion creep) and John Naliboff (combining plastic yielding and creep) in implementing similar available algorithms into ASPECT during the writing of this article but after our running of the experiments. Figures were created using the open-source software ParaView, Inkscape and gnuplot.

Edited by: Taras Gerya

Reviewed by: Dave May and Boris Kaus

\section{References}

Andrews, E. R. and Billen, M. I.: Rheologic controls on the dynamics of slab detachment, Tectonophysics, 464, 60-69, 2009.

Androvicova, A., Cizkova, H., and van den Berg, A. P.: The effects of rheological decoupling on slab deformation in the Earth's upper mantle, Stud. Geophys. Geod., 57, 460-481, https://doi.org/10.1007/s11200-012-0259-7, 2013.

Arndt, D., Bangerth, W., Davydov, D., Heister, T., Heltai, L., Kronbichler, M., Maier, M., Pelteret, J.-P., Turcksin, B., and Wells, D.: The deal.II Library, Version 8.5, J. Numer. Math., 24, 135-141, https://doi.org/10.1515/jnma-2016-1045, 2017.
Bangerth, W., Hartmann, R., and Kanschat, G.: deal.II - a general purpose object oriented finite element library, ACM Trans. Math. Softw., 33, 24/1-24/27, 2007.

Bangerth, W., Dannberg, J., Gassmöller, R., Heister, T., et al.: ASPECT: Advanced Solver for Problems in Earth's ConvecTion, User manual, Computational Infrastructure in Geodynamics, https://doi.org/10.6084/m9.figshare.4865333, 2017a.

Bangerth, W., Dannberg, J., Gassmöller, R., Heister, T., et al.: ASPECT v1.5.0 [software], Computational Infrastructure for Geodynamics, https://doi.org/10.5281/zenodo.344623, 2017b.

Baumgardner, J. R.: Three-dimensional treatment of convective flow in the earth's mantle, J. Stat. Phys., 39, 501-511, 1985.

Braun, J.: Three-dimensional numerical simulations of crustal-scale wrenching using a non-linear failure criterion, J. Struct. Geol., 16, 1173-1186, 1994.

Braun, J. and Beaumont, C.: Three-dimensional numerical experiments of strain partitioning at oblique plate boundaries: Implications for contrasting tectonic styles in the southern Coast Ranges, California, and central South Island, New Zealand, J. Geophys. Res.-Solid Earth, 100, 18059-19074, https://doi.org/10.1029/95JB01683, 1995.

Braun, J., Thieulot, C., Fullsack, P., DeKool, M., Beaumont, C., and Huismans, R. S: DOUAR: A new threedimensional creeping flow numerical model for the solution of geological problems, Phys. Earth Planet. In., 171, 76-91, https://doi.org/10.1016/j.pepi.2008.05.003, 2008.

Buiter, S. J. H.: A review of brittle compressional wedge models, Tectonophysics, 530-531, 1-17, 2012.

Buiter, S. J. H., Babeyko, A. Y., Ellis, S., Gerya, T. V., Kaus, B. J. P., Kellner, A., Schreurs, G., and Yamada, Y.: The numerical sandbox: comparison of model results for a shortening and an extension experiment, in: Analogue and Numerical Modelling of Crustal-Scale Processes, edited by: Buiter, S. J. H. and Schreurs, G., vol. 253, pp. 29-64, Geological Society, London, Special Publications, 2006.

Burkett, E. R. and Billen, M. I.: Dynamics and implications of slab detachment due to ridge-trench collision, J. Geophys. Res., 114, B12402, https://doi.org/10.1029/2009JB006402, 2009.

Burkett, E. R. and Billen, M. I.: Three-dimensionality of slab detachment due to ridge-trench collision: Laterally simultaneous boudinage versus tear propagation, Geochem. Geophy. Geosy., 11, Q11012, https://doi.org/10.1029/2010GC003286, 2010.

Burov, E.: Rheology and strength of the lithosphere, Mar. Petrol. Geol., 28, 1402-1443, https://doi.org/10.1016/j.marpetgeo.2011.05.008, 2011.

Burstedde, C., Ghattas, O., Gurnis, M., Stadler, G., Tan, E., Tu, T., Wilcox, L. C., and Zhong, S.: Scalable Adaptive Mantle Convection Simulation on Petascale Supercomputers, in: 2008 SC - International Conference for High Performance Computing, Networking, Storage and Analysis, IEEE, 1-15, https://doi.org/10.1109/SC.2008.5214248, 2008.

Burstedde, C., Wilcox, L., and Ghattas, O.: p4est: Scalable algorithms for parallel adaptive mesh refinement on forests of octrees, SIAM Journal on Scientific Computing, 33, 1103-1133, 2011.

Capitanio, F. A. and Faccenda, M.: Complex mantle flow around heterogeneous subducting oceanic plates, Earth Planet. Sci. Lett., 353-354, 29-37, 2012.

Capitanio, F. A. and Replumaz, A.: Subduction and slab breakoff controls on Asian indentation tectonics and Himalayan western 
syntaxis formation, Geochem. Geophy. Geosy., 353-354, 29-37, https://doi.org/10.1016/j.epsl.2012.07.042, 2013.

Chertova, M. V., Geenen, T., van den Berg, A., and Spakman, W.: Using open sidewalls for modelling self-consistent lithosphere subduction dynamics, Solid Earth, 3, 313-326, https://doi.org/10.5194/se-3-313-2012, 2012.

Chertova, M. V., Spakman, W., Geenen, T., van den Berg, A. P., and van Hinsbergen, D. J. J.: Underpinning tectonic reconstructions of the western Mediterranean region with dynamic slab evolution from 3-D numerical modeling, J. Geophys. Res.-Solid Earth, 119, 5876-5902, https://doi.org/10.1002/2014JB011150, 2014a.

Chertova, M. V., Spakman, W., van den Berg, A. P., and van Hinsbergen, D. J. J.: Absolute plate motions and regional subduction evolution, Geochem. Geophy. Geosy., 15, 3780-3792, https://doi.org/10.1002/2014GC005494, 2014b.

Choi, E. and Petersen, K. D.: Making Coulomb angle-oriented shear bands in numerical tectonic models, Tectonophysics, 657, 94101, https://doi.org/10.1016/j.tecto.2015.06.026, 2015.

Christensen, U. R. and Yuen, D. A.: Layered convection induced by phase transitions, J. Geophys. Res., 90, 10291-10300, 1985.

Christiansen, E. and Pedersen, O. S.: Automatic mesh refinement in limit analysis, Int. J. Numer. Meth. Eng., 6, 1331-1346, https://doi.org/10.1002/1097-0207(20010228)50:6<1331::AIDNME46>3.0.CO;2-S, 2001.

Cizkova, H., van den Berg, A. P., Spakman, W., and Matyska, C.: The viscosity of the Earth's lower mantle inferred from sinking speed of subducted lithosphere, Phys. Earth Planet. In., 200-201, 56-62, 2012.

Crameri, F. and Tackley, P. J.: Spontaneous development of arcuate single-sided subduction in global 3-D mantle convection models with a free surface, J. Geophys. Res.-Solid Earth, 119, 59215942, https://doi.org/10.1002/2014JB010939, 2014.

Crameri, F., Schmeling, H. A., Golabek, G. J., Duretz, T., Orendt, R., Buiter, S. J. H., May, D. A., Kaus, B., Gerya, T. V., and Tackley, P. J.: A comparison of numerical surface topography calculations in geodynamic modelling: an evaluation of the 'sticky air' method, Geophys. J. Int., 189, 38-54, 2012.

Dabrowski, M., Krotkiewski, M., and Schmid, D.: MILAMIN: MATLAB-based finite element method solver for large problems, Geochem. Geophy. Geosy., 9, Q04030, https://doi.org/10.1029/2007GC001719, 2008.

Dannberg, J. and Heister, T.: Compressible magma/mantle dynamics: 3d, adaptive simulations in ASPECT, Geophys. J. Int., 207, 1343-1366, https://doi.org/10.1093/gji/ggw329, 2016.

Davies, D. R., Wilson, C. R., and Kramer, S. C.: Fluidity: a fully unstructured anisotropic adaptive mesh computational modeling framework for geodynamics, Geochem. Geophy. Geosy., 120, Q06001, https://doi.org/10.1029/2011GC003551, 2011.

Davies, D. R., Davies, J. H., Bollada, P. C., Hassan, O., Morgan, K., and Nithiarasu, P.: A hierarchical mesh refinement technique for global 3-D spherical mantle convection modelling, Geosci. Model Dev., 6, 1095-1107, https://doi.org/10.5194/gmd-6-10952013, 2013.

Davis, R. O. and Selvadurai, A. P. S.: Plasticity and Geomechanics, Cambridge University Press, 2002.

de Souza Neto, E. A., Peric, D., and Owen, D. R. J.: Computational methods for plasticity, John Wiley \& Sons, Ltd, 2008.

Deubelbeiss, Y. and Kaus, B.: Comparison of Eulerian and Lagrangian numerical techniques for the Stokes equations in the presence of stronly varying viscosity, Phys. Earth Planet. In., 171, 92-111, 2008.

Donea, J. and Huerta, A.: Finite element methods for flow problems, John Wiley \& Sons, Ltd, https://doi.org/10.1002/0470013826, 2003.

Duretz, T., Gerya, T. V., and May, D. A.: Numerical modelling of spontaneous slab breakoff and subsequent topographic response, Tectonophysics, 502, 244-256, https://doi.org/10.1016/j.tecto.2010.05.024, 2011.

Duretz, T., Schmalholz, S. M., and Gerya, T. V.: The dynamics of slab detachment, Geochem. Geophy. Geosy., 13, Q03020, https://doi.org/10.1029/2011GC004024, 2012.

Duretz, T., Gerya, T. V., and Spakman, W.: Slab detachment in laterally varying subduction zones: 3-D numerical modeling, Geophys. Res. Lett., 41, 1951-1956, 2014.

Farrington, R. J., Moresi, L. N., and Capitanio, F. A.: The role of viscoelasticity in subducting plates, Geochem. Geophy. Geosy., 15, 4291-4304, 2014.

Fleck, N. and Hutchinson, J.: A reformulation of strain gradient plasticity, J. Mech. Phys. Solids, 49, 2245-2271, https://doi.org/10.1016/S0022-5096(01)00049-7, 2001.

Fourel, L., Goes, S., and Morra, G.: The role of elasticity in slab bending, Geochem. Geophy. Geosy., 15, 4507-4525, 2014.

Fraters, M., Bangerth, W., Thieulot, C., and Spakman, W.: Newton Solver Stabilization for Stokes Solvers in Geodynamic Problems, Geophys. Res. Abstr., 19, EGU2017-13556, 2017.

Garel, F., Goes, S., Davies, D. R., Davies, J. H., Kramer, S. C., and Wilson, C. R.: Interaction of subducted slabs with the mantle transition-zone: a regime diagram from 2D thermo-mechanical models with a mobile trench and an overriding plate, Geochem. Geophy. Geosy., 15, 1739-1765, https://doi.org/10.1002/2014GC005257, 2014.

Gassmöller, R., Heien, E., Puckett, E. G., and Bangerth, W.: Flexible and scalable particle-in-cell methods for massively parallel computations, ArXiv e-prints, available at: https://arxiv.org/abs/ 1612.03369, 2016.

Gerbault, M., Poliakov, A. N. B., and Daignieres, M.: Prediction of faulting from the theories of elasticity and plasticity: what are the limits?, J. Struct. Geol., 20, 301-330, 1998.

Gerya, T. V.: Introduction to Numerical Geodynamic Modelling, Cambridge University Press, 2010.

Gerya, T. V. and Yuen, D. A.: Robust characteristics method for modelling multiphase visco-elasto-plastic thermo-mechanical problems, Phys. Earth Planet. In., 163, 83-105, 2007.

Gerya, T. V., Yuen, D. A., and Maresh, W. V.: Thermomechanical modelling of slab detachment, Earth Planet. Sci. Lett., 226, 101116, 2004.

Gerya, T. V., May, D. A., and Duretz, T.: An adaptive staggered grid finite difference method for modeling geodynamic Stokes flows with strongly variable viscosity, Geochem. Geophy. Geosy., 14, 4, https://doi.org/10.1002/ggge.20078, 2013.

Glerum, A.: Source code, input files and postprocessing scripts, available at: https://doi.org/10.5281/zenodo.852654, August 2017.

Gourvenec, S., Randolph, M., and Kingsnorth, O.: Undrained bearing capacity of square and rectangular footings, Int. J. Geomechanics, 6, 147-157, https://doi.org/10.1061/(ASCE)15323641(2006)6:3(147), 2006. 
Guermond, J.-L., Pasquetti, R., and Popov, B.: Entropy viscosity method for nonlinear conservation laws, J. Comput. Phys., 230, 4248-4267, 2011.

He, Y., Puckett, E. G., and Billen, M. I.: A discontinuous Galerkin method with a bound preserving limiter for the advection of nondiffusive fields in solid Earth geodynamics, Phys. Earth Planet. In., 263, 23-37, https://doi.org/10.1016/j.pepi.2016.12.001, 2017.

Heister, T., Dannberg, J., Gassmöller, R., and Bangerth, W.: High accuracy mantle convection simulation through modern numerical methods - II: realistic models and problems, Geophys. J. Int., 210, 833-851, https://doi.org/10.1093/gji/ggx195, 2017.

Heroux, M. A. and Willenbring, J. M.: A new overview of the Trilinos Project, Scientific Programming, 20, 83-88, https://doi.org/10.3233/SPR-2012-0355, 2012.

Heroux, M. A., Bartlett, R. A., Howle, V. E., Hoekstra, R. J., Hu, J. J., Kolda, T. G., Lehoucq, R. B., Long, K. R., Pawlowski, R. P., Phipps, E. T., Salinger, A. G., Thornquist, H. K., Tuminaro, R. S., Willenbring, J. M., Williams, A., and Stanley, K. S.: An overview of the Trilinos project, ACM Trans. Math. Softw., 31, 397-423, 2005.

Hillebrand, B., Thieulot, C., Geenen, T., van den Berg, A. P., and Spakman, W.: Using the level set method in geodynamical modeling of multi-material flows and Earth's free surface, Solid Earth, 5, 1087-1098, https://doi.org/10.5194/se-5-10872014, 2014.

Hirth, G. and Kohlstedt, D.: Rheology of the upper mantle and the mantle wedge: a view from the experimentalists, in: Inside the Subduction Factory, edited by: Eiler, J., vol. 183 of Geophysical Monograph, American Geophysical Union, 2003.

Huh, H., Lee, C. H., and Yang, W. H.: A general algorithm for plastic flow simulation by finite element limit analysis, Int. J. Solids Struct., 36, 1193-1207, 1999.

Ismail-Zadeh, A. and Tackley, P. J.: Computational Methods for Geodynamics, Cambridge University Press, 2010.

Kachanov, L. M.: Fundamentals of the Theory of Plasticity, Dover Publications, Inc., 2004.

Karato, S.: Deformation of Earth Materials: An Introduction to the Rheology of Solid Earth, Cambridge University Press, 2008.

Karato, S. and Wu, P.: Rheology of the Upper Mantle: A Synthesis, Science, 260, 771-778, 1993.

Kaus, B.: Factors that control the angle of shear bands in geodynamic numerical models of brittle deformation, Tectonophysics, 484, 36-47, 2010.

Kaus, B., Mühlhaus, H.-B., and May, D. A.: A stabilization algorithm for geodynamic numerical simulations with a free surface, Phys. Earth Planet. In., 181, 12-20, https://doi.org/10.1016/j.pepi.2010.04.007, 2010.

Kaus, B. J. P., Popov, A. A., Baumann, T. S., Püsök, A. E., Bauville, A., Fernandez, N., and Collignon, M.: Forward and inverse modelling of lithospheric deformation on geological timescales, no. 8 in NIC Series, Forschungszentrum Jülich GmbH, 2016.

Kronbichler, M., Heister, T., and Bangerth, W.: High accuracy mantle convection simulation through modern numerical methods, Geophys. J. Int., 191, 12-29, 2012.

Lee, J., Salgado, R., and Kim, S.: Bearing capacity of circular footings under surcharge using state-dependent finite element analysis, Comput. Geotech., 32, 445-457, 2005.
Lemiale, V., Mühlhaus, H.-B., Moresi, L., and Stafford, J.: Shear banding analysis of plastic models formulated for incompressible viscous flows, Phys. Earth Planet. In., 171, 177-186, 2008.

Lliboutry, L. A.: Very slow flow of fluids: Basics of modeling in geodynamics and glaciology, chap. The rigid-plastic model, pp. 393-401, Martinus Nijhoff Publishers, 1987.

Malatesta, C., Gerya, T. V., Crispini, L., Federico, L., and Capponi, G.: Oblique subduction modelling indicates along-trench tectonic transport of sediments, Nature Communications, 4, 2456, https://doi.org/10.1038/ncomms3456, 2013.

Mason, W. G., Moresi, L., Betss, P., and Miller, M. S.: Threedimensional numerical models of the influence of a buoyant oceanic plateau on subduction zones, Tectonophysics, 483, 7179, 2010.

May, D. A., Brown, J., and Le Pourhiet, L.: A scalable, matrix-free multigrid precondition for finite element discretizations of heterogeneous Stokes flow, Comput. Methods Appl. M., 290, 496523, 2015.

Moresi, L., Zhong, S., and Gurnis, M.: The accuracy of finite element solutions of Stokes' flow with strongly varying viscosity, Phys. Earth Planet. In., 97, 83-94, 1996.

Moresi, L., Quenette, S., Lemiale, V., Mériaux, C., Appelbe, B., and Mühlhaus, H.-B.: Computational approaches to studying nonlinear dynamics of the crust and mantle, Phys. Earth Planet. In., 163, 69-82, 2007.

Popov, A. A. and Sobolev, S. V.: SLIM3D: a tool for the threedimensional thermomechanical modeling of the lithospheric deformation with elasto-visco-plastic rheology, Phys. Earth Planet. In., 171, 55-75, https://doi.org/10.1016/j.pepi.2008.03.007, 2008.

Ranalli, G.: Rheology of the Earth, Chapman and Hall, London, 1995.

Rose, I., Buffett, B. A., and Heister, T.: Stability and accuracy of free surface time integration in viscous flows, Phys. Earth Planet. In., 262, 90-100, 2017.

Rudi, J., Malossi, A. C. I., Isaac, T., Stadler, G., Gurnis, M., Staar, P. W. J., Ineichen, Y., Bekas, C., Curioni, A., and Ghattas, O.: An Extreme-scale Implicit Solver for Complex PDEs: Highly Heterogeneous Flow in Earth's Mantle, in: Proceedings of the International Conference for High Performance Computing, Networking, Storage and Analysis, SC '15, pp. 5:1-5:12, ACM, New York, NY, USA, https://doi.org/10.1145/2807591.2807675, 2015.

Schellart, W. P. and Moresi, L.: A new driving mechanism for backarc extension and backarc shortening through slab sinking induced toroidal and poloidal mantle flow: Results from dynamic subduction models with an overriding plate, J. Geophys. Res., 118, 1-28, 2013.

Schellart, W. P., Freeman, J., Stegman, D. R., Moresi, L., and May, D.: Evolution and diversity of subduction zones controlled by slab width, Nature Lett., 446, 308-311, https://doi.org/10.1038/nature05615, 2007.

Schmalholz, S. M.: A simple analytical solution for slab detachment, Earth Planet. Sci. Lett., 304, 45-54, 2011.

Schmeling, H. A., Babeyko, A. Y., Enns, A., Faccenna, C., Funiciello, F., Gerya, T., Golabek, G. J., Grigull, S., Kaus, B. J. P., Morra, G., Schmalholz, S. M., and van Hunen, J.: A benchmark comparison of spontaneous subduction models-Towards a free surface, Phys. Earth Planet. In., 171, 198-223, 2008. 
Schreurs, G., Buiter, S. J. H., Boutelier, D., Corti, G., Costa, E., Cruden, A. R., Daniel, J.-M., Hoth, S., Koyi, H. A., Kukowski, N., Lohrmann, J., Ravaglia, A., Schlische, R. W., Withjack, M. O., Yamada, Y., Cavozzi, C., Del Ventisette, C., Brady, J. A. E., Hoffmann-Rothe, A., Mengus, J.-M., Montanari, D., and Nilforoushan, F.: Analogue benchmarks of shortening and extension experiments, in: Analogue and Numerical Modelling of CrustalScale Processes, edited by: Buiter, S. J. H. and Schreurs, G., Geological Society, London, Special Publications, 253, 1-27, https://doi.org/10.1144/GSL.SP.2006.253.01.01, 2006.

Schubert, G., Turcotte, D. L., and Olson, P.: Mantle Convection in the Earth and Planets, Cambridge University Press, 2001.

Spiegelman, M., May, D. A., and Wilson, C. R.: On the solvability of incompressible Stokes with viscoplastic rheologies in geodynamics, Geochem. Geophy. Geosy., 17, 2213-2238, https://doi.org/10.1002/2015GC006228, 2016.

Stegman, D. R., Freeman, J., Schellart, W. P., Moresi, L., and May, D. A.: Influence of trench width on subduction hinge retreat rates in 3-D models of slab rollback, Geochem. Geophy. Geosy., 7, Q03012, https://doi.org/10.1029/2005GC001056, 2006.

Stegman, D. R., Schellart, W. P., and Freeman, J.: Competing influences of plate width and far-field boundary conditions on trench migration and morphology of subducted slabs in the upper mantle, Tectonophysics, 483, 46-57, 2010.

Sternai, P., Jolivet, L., Menant, A., and Gerya, T. V.: Driving the upper plate surface deformation by slab rollback and mantle flow, Earth Planet. Sci. Lett., 405, 110-118, 2014.

Thieulot, C.: FANTOM: Two- and three-dimensional numerical modelling of creeping flows for the solution of geological problems, Phys. Earth Planet. In., 188, 47-68, 2011.

Thieulot, C.: ELEFANT: a user-friendly multipurpose geodynamics code, Solid Earth Discuss., https://doi.org/10.5194/sed-6-19492014, in review, 2014.

Thieulot, C., Fullsack, P., and Braun, J.: Adaptive octreebased finite element analysis of two- and three-dimensional indentation problems, J. Geophys. Res., 113, B12207, https://doi.org/10.1029/2008JB005591, 2008.

Tosi, N., Stein, C., Noack, L., Hüttig, C., Maierova, P., Samual, H., Davies, D. R., Wilson, C. R., Kramer, S. C., Thieulot, C., Glerum, A., Fraters, M., Spakman, W., Rozel, A., and Tackley, P. J.: A community benchmark for viscoplastic thermal convection in a 2-D square box, Geochem. Geophy. Geosy., 16, 21752196, 2015. van den Berg, A., van Keken, P., and Yuen, D. A.: The effects of a composite non-Newtonian and Newtonian rheology on mantle convection, Geophys. J. Int., 115, 62-78, 1993.

van Hunen, J. and Allen, M. B.: Continental collision and slab break-off: A comparison of 3-D numerical models with observations, Earth Planet. Sci. Lett., 302, 27-37, 2011.

Vermeer, P. A.: The orientation of shear bands in bi-axial tests, Géotechnique, 40, 223-236, 1990.

von Tscharner, M., Schmalholz, S. M., and Duretz, T.: Threedimensional necking during viscous slab detachment, Geophys. Res. Lett., 41, 4194-4200, 2014.

Willett, S. D.: Dynamic and kinematic growth and change of a Coulomb wedge, in: Thrust tectonics, edited by: McClay, K. R., pp. 19-32, Chapman and Hall, New York, 1992.

Wilson, C. R., Spiegelman, M., and van Keken, P. E.: TerraFERMA: The Transparent Finite Element Rapid Model Assembler for multiphysics problems in Earth sciences, Geochem. Geophy. Geosy., 18, 769-810, https://doi.org/10.1002/2016GC006702, 2017.

Wortel, M. J. R. and Spakman, W.: Subduction and slab detachment in the Mediterranean-Carpathian region, Science, 290, 1910, https://doi.org/10.1126/science.290.5498.1910, 2000.

Yamato, P., Husson, L., Braun, J., Loiselet, C., and Thieulot, C.: Influence of surrounding plates on 3D subduction dynamics, Geophys. Res. Lett., 36, L07303, https://doi.org/10.1029/2008GL036942, 2009.

Yu, X. and Tin-Loi, F.: A simple mixed finite element for static limit analyis, Computers and Structures, 84, 1906-1917, 2006.

Zhang, S. and O'Neill, C.: The early geodynamic evolution of Mars-type planets, Icarus, 265, 187-208, https://doi.org/10.1016/j.icarus.2015.10.019, 2016.

Zhong, S.: Constraints on thermochemical convection of the mantle from plume heat flux, plume excess temperature, and upper mantle temperature, J. Geophys. Res., 111, B04409, https://doi.org/10.1029/2005JB003972, 2006.

Zienkiewicz, O. C., Huang, M., and Pastor, M.: Localization problems in plasticity using finite elements with adaptive remeshing, Numerical and Analytical Methods in Geomechanics, 19, 127$148,1995$. 